\title{
Internet Use and Well-being: A Survey and a Theoretical Framework
}

\author{
Fulvio Castellacci and Vegard Treito
}

TIK Centre, University of Oslo

Research Policy, 2018, forthcoming

\begin{abstract}
How does Internet use affect well-being? This paper presents a survey of the literature investigating this question, and it develops a framework to analyze both positive effects and potential risks. We point out four distinct channels through which Internet can shape well-being: it changes time use patterns, creates new activities, facilitates access to information, and acts as powerful communication tool. We show how these four channels impact well-being in distinct domains of life. A central point emerging from the literature review is that the effects of Internet on well-being are mediated by a set of personal characteristics that are specific to each individual: psychological functioning, capabilities, and framing conditions (culture and beliefs). Hence, it is the interaction between human beings' activities in distinct domains of life and their own personal characteristics that explains why the use of Internet has stronger positive effects for some individuals and social groups than others.
\end{abstract}

Key words: ICTs; Internet; innovation; well-being

JEL codes: O33; I31; D31 


\section{Introduction}

Since the times of its emergence in the late 1970s, the innovation studies literature has had a predominant interest in how the production and diffusion of new advanced technologies affect economic performance - and in particular economic growth, competitiveness and employment. During the last three decades, innovation studies have developed in a number of different directions, but the key underlying motivation that innovation spurs economic performance has implicitly been a common theme in different strands of research (Fagerberg et al., 2005).

Other potentially relevant impacts of new technologies - and in particular on the users' wellbeing - have largely been neglected (Castellacci et al., 2005). In a recent appraisal of research in innovation studies, Ben Martin points out twenty challenges for future research, one of them being precisely the need to investigate how advanced technologies affect human well-being:

"Innovation scholars will need to shift the focus of our empirical work from innovation for wealth to innovation for well-being" (Martin, 2016, 12).

What is well-being, and why is it important for innovation researchers to study it? A large literature has in recent years investigated the extent to which well-being differs across individuals, social groups and countries, and the set of factors that may explain these differences. Among other factors, these studies have focused on differences in absolute and relative income among individuals, their work life quality, their social relationships and the characteristics and quality of the physical and socio-institutional environment in which they live (see e.g. the

comprehensive overviews in Frey and Stutzer (2002); Dolan et al. (2008); Layard (2011); and MacKerron (2012)).

Interestingly, this literature has flourished independently from innovation studies, and the two strands of research have not interacted with each other. In well-being studies, technological innovation is definitively not one of the many variables that have been studied in the mainstream explanatory framework. Analogously, innovation studies have very seldom investigated whether and how new technologies affect well-being (notable exceptions are the recent works of Dolan and Metcalfe, 2012; Binder, 2013; and Engelbrecht, 2014). An implicit assumption in innovation research is that new technologies foster economic performance (economic growth and competitiveness), and the latter does in turn lead to increased well-being for individuals. 
However, the well-being literature shows that this is not necessarily the case, and that the relationship between economic outcomes and individuals' well-being is much more complex. It is therefore crucial to investigate the links between innovation, economic performance and wellbeing.

Based on this motivation, the present paper focuses on one of the key technological paradigms of our times: Information and Communication Technologies (ICTs). These have in the last few decades transformed substantially several aspects of our everyday life, enabling a terrific progress for human beings both at the workplace and as individual consumers, agents and citizens. Innovation studies have extensively investigated the emergence and diffusion of ICTs, and particularly focused on the pervasive economic effects that these general-purpose technologies have on different sectors of the economy (Antonelli, 1998; Dalum et al., 1999; Freeman \& Louçã, 2001; Castellacci, 2006, 2008).

One of the key technological trajectories within ICTs is represented by the Internet. This has by now become a fundamental tool in our everyday life. Examples of the pervasiveness of Internet technologies abound. Individuals can now use e-commerce to buy and sell goods and services; carry out financial transactions through online banking; search information, access data and organize databases; and communicate with other friends, family and colleagues through e-mail, Skype, and social media. Despite the widespread diffusion and great relevance of Internet technologies, however, there is still limited knowledge about the impacts that these have on individuals' well-being. What are the effects of Internet use on well-being?

Research on the effects of Internet on well-being is quite fragmented. Several papers in the fields of psychology and computer science have recently investigated how the use of Internet and social networking sites shape human behavior and social interactions (e.g Valkenburg et al., 2006). Other papers in the economics of happiness have used large-scale survey datasets to study the relationship between ICTs and well-being (Kavetsos and Koutroumpis, 2011; Graham \& Nikolova, 2013; Penard et al., 2013; Ganju et al., 2015). However, many other potentially relevant channels through which Internet use shapes well-being have not been investigated yet. At present, research on this important theme lacks a coherent and holistic framework that may combine insights from different disciplines and guide future research.

The objective of this paper is to carry out a survey of extant literature on the relationships between Internet use and well-being. We argue that the main relevant mechanisms can be 
summarized and grouped into four distinct channels: Internet can shape well-being by enabling time-saving and changing time use patterns, leading to the introduction of new activities, enabling a greater access to information, and providing new communication tools. By using this typology as a main conceptual device, our literature review leads to the main conclusion that the effects of Internet on well-being are mediated by a set of personal characteristics that are specific to each individual, namely psychological functioning, capabilities, culture and beliefs (see Ryff and Singer, 2008). Hence, the interaction between human beings' activities in distinct domains of life and their individual personal characteristics explains why Internet use has stronger positive effects for some individuals and social groups than others.

The main contribution of the paper is twofold. First, we provide a systematic review of a literature that studies a question of great societal relevance, and which is of high interest to innovation studies research. Second, we build up an interdisciplinary framework that combines insights from different strands of research and various disciplines interested in human well-being such as economics, organizational studies, psychology and information systems research. The framework presented in this paper thus represents an attempt to bring together the heterogeneous and fragmented extant research on this theme and provide a more general structure to foster future research on this topic.

The paper is organized as follows. Section 2 outlines the concept of well-being and the main research traditions that study it. Section 3 provides a general overview of the empirical literature on Internet and well-being, pointing out two main recent strands of research that investigate this new topic. Section 4 puts forward a typology of effects of Internet on well-being, which represents our conceptual device to analyze the relevant literature. Section 5 presents a detailed literature review that is organized by focusing on individuals' different domains of life (private life, work life, external environment). Section 6 shifts the focus to literature that has analyzed the effects of Internet through personal characteristics (psychological functioning, capabilities, culture and beliefs). Section 7 summarizes the main conclusions that emerge from this survey. Section 8 concludes the paper and points out a topic for future research on Internet and wellbeing. 


\section{Well-being: definitions and relevant literature}

Two different research traditions have investigated well-being and its determinants: subjective well-being (SWB) and objective well-being (OWB). The former is called "subjective" because it studies well-being as perceived by each individual, whereas the latter is named "objective" because it focuses on a set of characteristics that are considered to be necessary for individuals to lead a good life (Gasper, 2005; Guillen-Royo, 2007).

The SWB approach. The classical philosophical origins of this view are rooted in Aristippus' hedonism in ancient Greek philosophy, which has later been revived and developed further by Jeremy Bentham's utilitarianism, and more recently by hedonic psychology (Kahneman et al., 1999). Empirical studies in the SWB approach typically seek to investigate two distinct aspects of individuals' well-being (Kahneman \& Krueger, 2006): (1) hedonic (or emotional) well-being, which is focused on experienced happiness and short-run feelings of pleasure, and it can be defined as «the frequency and intensity of experiences of joy, fascination, anxiety, sadness, anger, and affection that makes life pleasant or unpleasant» (Kahneman \& Deaton, 2010, 16489); (2) evaluative well-being, which focuses on long term self-assessment of life satisfaction, and it is defined as «the thoughts that people have about their life when they think about it» (Kahneman \& Deaton, 2010, 16489).

A large strand of research, rooted at the intersection between economics and psychology, has extensively investigated the factors that explain differences in the SWB reported by individuals in different social groups and in different countries (Frey \& Stutzer, 2002; Layard, 2011). In a comprehensive survey of the field, Ryan and Deci (2001) point out that, in spite of the large heterogeneity of focus and approaches that are adopted in this literature, the underlying explanatory model that is typically used by these studies is the so-called "expectancy-value approach" (Oishi et al., 1999), according to which "well-being is a function of expecting to attain (and/or attaining) the outcomes one values, whatever those might be" (Ryan \& Deci, 2001, 145). Empirical research on the determinants of SWB has been fostered in recent years by the increasing availability of large scale surveys (e.g. World Value Surveys; European Social Surveys; Gallup World Poll), and it has considered a number of distinct dimensions (see reviews in Dolan et al. (2008); and MacKerron (2012)). Specifically, different strands of research have investigated different factors that affect well-being in distinct «domains of life» (Binder, 2013). 
In SWB studies, one of the domains of life that has received most scholarly attention is the economic domain. Through their work, individuals earn an income that is spent on consumption items, which make it possible to fulfill their basic needs as well as to finance spare time activities. Further, in addition to absolute income and consumption, SWB is substantially affected by relative income, i.e. the extent to which an individual's income is above, or below, the average of her reference group (e.g. neighbors, family, colleagues; see Clark et al. (2008); Clark and Senik (2010); Easterlin (1995); Senik (2005)). A second relevant domain of life that has been studied in happiness research is the quality of working life. Different jobs are characterized by distinct working tasks, and different degrees of creativity and autonomy, which affect employees' worklife balance and job satisfaction (Dolan \& Metcalfe, 2012; Erdogan et al., 2012). Other domains of life that have been found to be crucial for individuals' SWB refer to their social life (e.g. family status; community life; see Layard (2011)), the physical environment in which they live (location, quality, climate); the socio-institutional environment that characterize their country (governance, trust, crime, social capital; MacKerron (2012)); and the social and national culture, which affects individuals' perception of their own status (e.g. religious beliefs; political attitudes; national culture; Frey and Stutzer (2002)).

The OWB approach. The second research tradition comprises different strands of research which have in common the focus on a set of characteristics that are regarded as necessary for individuals to lead a good life, and how these "objective" characteristics can be empirically measured (Gasper, 2005; Guillen-Royo, 2009). A key concept in this tradition is so-called eudaimonic well-being. Rooted in Aristotle's ethics, and later revived and extended in the philosophical school of eudaimonism (Waterman, 1984, 1993), this approach defines well-being as the extent to which individuals are able to realize their own inner potential (also called "daimon" or "true nature"). The focus here is not on well-being as perceived by each individual, but rather on "healthy, congruent and vital functioning" (Ryan \& Deci, 2001, 147), which is typically assessed in terms of individuals' positive psychological functioning, meaningfulness and purpose of life.

Research in this field is mostly rooted in personality and social psychology. An influential model investigating the factors shaping individuals' eudaimonic well-being is self-determination theory (Deci \& Ryan, 2000). According to this, human beings have three basic psychological needs that they inherently need to fulfill: autonomy, competence and relatedness. The fulfillment of these 
three needs is essential for psychological growth, integrity, vitality and well-being (Deci \& Ryan, 2000, 147). Hence, according to this theory, the social, cultural and contextual factors that characterize different domains of life do not have a direct effect on individuals' well-being (as argued in the SWB approach), but they rather shape well-being by affecting the extent to which the fulfillment of these three basic needs is facilitated (or hampered). These basic needs, in turn, shape individuals' motivation (intrinsic vs. extrinsic), the formulation of personal goals, and thereby the ability to realize individuals' inner potential.

A related model is the one presented by Ryff (1989) and Ryff and Singer (2008), which argue that well-being is a multi-dimensional construct that can be defined in terms of six dimensions: purpose of life, personal growth, positive relations with others, environmental mastery, autonomy and self-acceptance. It is individuals' attitude and ability to cultivate these personal characteristics that enable them to shape their life purpose and realize their human potential (Ryff \& Singer, 2008).

There is also a different research tradition, rooted in human development research, that emphasizes the importance of capabilities (Sen, 1985, 1993). Capabilities can be defined as the set of opportunities that individuals have to carry out a series of functioning and everyday activities, and that are therefore necessary for well-being. Crucial examples of relevant capabilities that enable human beings to realize their potential are in particular health and education, which are important conditions that enable individuals to take full advantage of the daily opportunities to conduct a good and meaningful life (Borghesi \& Vercelli, 2012; Graham \& Nikolova, 2015). A large strand of empirical research has developed these conceptual insights and studied objective indicators of quality of life and well-being. Although the capability approach is not rooted in psychological research, its emphasis on the fulfillment of basic (physiological and psychological) needs, and its endeavor to define a set of objective characteristics that are necessary to lead a good life make it close to the eudaimonic approach to well-being.

Before moving forward, it is important to point out that - although the SWB and OWB schools have different philosophical origins and are currently being developed in distinct fields of research, the two views are not in contrast with each other, and there are important conceptual similarities and common points (Ryan and Deci, 2001). Empirically, different indicators of SWB 
and OWB are correlated (Graham and Nikolova, 2015). ${ }^{1}$ For these reasons, our assumption in this paper is that both of the approaches provide crucial insights that are important to understand how Internet affects well-being. The remainder of this article will therefore consider both subjective and objective notions of well-being, and discuss how Internet shapes these.

\section{An overview of the literature on Internet and well-being}

We begin our literature review by providing a general overview of recent research on Internet and well-being. Our survey of the literature collected information on relevant studies on this topic. The search process made use of the following search engines and paper archives: Googleand Google Scholar; the JSTOR-, IDEAS- and ScienceDirect Journal databases. This extensive search strategy enabled us to capture both formally published papers as well as a few recent working papers. After having identified and selected an initial number of studies, we scanned their reference lists in order to identify more papers and refine the data collection. The main selection criterion was to consider all papers with the following three characteristics: (1) the dependent variable in the study is well-being; (2) the main explanatory variable is Internet use; (3) the study presents an empirical analysis of the relationship between Internet use and wellbeing.

Following these criteria, our literature search identified 54 relevant papers, published in the period between 1998 and 2017. These papers represent the core literature that is surveyed in the present article. Table 1 lists these 54 papers and provides a brief overview of some of their features. ${ }^{2}$ We divide these articles into two distinct groups: the first refers to papers within economics and management research, whereas the second group relates to articles within computer science and psychology.

\footnotetext{
${ }^{1}$ Kahneman and Deaton (2010) show for instance that indicators of hedonic (or emotional) well-being share many of the same determinants as evaluative well-being (life satisfaction), although health is more closely related to the former and income and education to the latter. Graham and Nikolova (2015) point out that a set of objective measures of capabilities and means are correlated with both hedonic and evaluative well-being, although more strongly with the latter than the former.

${ }^{2}$ Fischer and Boer (2011) presented a comprehensive meta-analysis of well-being, wealth and autonomy. In the present paper, we are not able to carry out a quantitative meta-regression analysis, since the papers listed in table 1 use a variety of different measures and indicators - both for the dependent and explanatory variables - so that the estimated results are not strictly comparable to each other, and therefore not suitable for a meta regression analysis.
} 
The economics and management research on Internet use and well-being includes 24 papers. These are published in a variety of journals, among which for instance the Journal of Economic Behavior \& Organization, the Journal of Socio-Economics and Kyklos. These studies have a great deal of common characteristics. First, most of them are cross-country econometric analyses based on large global survey datasets that are publicly available (e.g. European Social Survey, Eurobarometer, Gallup World Poll). Second, the dependent variable refers in most cases to an evaluative notion of well-being (life satisfaction, or job satisfaction).

It is worth noting some examples of key papers in this research strand. Kavetsos and Koutrompis (2011) analyzed the relationships between mobile phones, computers with Internet connection and life satisfaction using the Eurobarometer dataset for the years 2005-2008. Penard et al. (2013) studied the effect of Internet use intensity in Luxembourg, using data from the European Value Survey in 2008. Graham and Nikolova (2013) and Ganju et al. (2015) carried out cross-country studies of the Internet-life satisfaction relationship, both of them using data from the Gallup World Poll. Ganju et al. (2015) point out some of the key mechanisms that explain this empirical relationship, which we will elaborate further in the next sections.

The second strand of research noted in table 1 refers to papers published in a research strand at the intersection between computer science and psychology. We have identified 30 relevant papers in this field. Although computer science and psychology are different disciplines, both of them have in recent years been interested in the way in which communication patterns are being transformed by the Internet and online interactions between individuals, and how these changes may affect well-being. A large number of journals have published research on this topic, and some of them are for instance Computers in Human Behavior, Cyberpsychology \& Behavior, and the Journal of Computer-Mediated Communication. Papers in this strand of research have three common characteristics. First, nearly all of them are based on own surveys done by the authors in specific national contexts rather than cross-country datasets. The great majority of studies are based on surveys done among University students in the US. Second, the dependent variable in these articles does often relate to a broader notion of psychological well-being (rather than only life satisfaction as in the first strand of research noted above). Third, although a number of different variables have been used to study Internet and online activities, one key dimension that has attracted a great deal of attention is the use of social network sites (SNS), given the great popularity that this new form of online communication has experienced in recent years. 
The brief overview presented in table 1 suggests also two reflections regarding the empirical methodologies used in these studies. The first is that the econometric analysis of the effects of Internet use on well-being should in principle take into consideration issues of selection bias and endogeneity, since it is reasonable to assume that there are systematic differences between users and non-users of Internet, and that omitted variables may possibly affect the reliability of the estimated relationship of interest. However, table 1 indicates that only a limited number of studies have considered this issue. The typical econometric strategy to tackle this has been to employ instrumental variables, which exploit some forms of exogenous variation that can explain Internet use differences among individuals. Examples of instrumental variables that have been used in this literature are broadband infrastructures in different regions (Hyll and Schneider, 2013; Bhuller et al., 2013; Sabatini and Sarracino, 2016; 2017), the country's slope of terrain (that affects investments in Internet infrastructure; Ganju et al., 2015), and peer effects in ICT use (Penard et al., 2013; Castellacci and Viñas-Bardolet, 2017).

A second methodological issue is that, as noted above, a large number of studies (particularly those within computer science and psychology) are based on own surveys carried out by the authors within a given national context (often the US), and a specific target group (typically University students). This raises the question of representativeness and generalizability of the results, i.e. to what extent the results of these works can be generalized to other countries and other social groups. These methodological considerations suggest that results of the surveyed literature should be interpreted with some caution, and particularly so for those works that do not provide robust and representative estimations of causal effects. Future research will have to replicate and extend extant studies in different geographical and socio-economic contexts.

\section{< Table 1 here >}

\section{The effects of Internet on well-being: a new typology}

The study of the effects of Internet use on well-being has to consider three important sources of heterogeneity. First, the effects of Internet on well-being do arguably differ depending on the specific life domain in which Internet is used (working life, private life, surrounding environment), and the specific personal characteristics and conditions that shape individuals' 
perception of their own status and well-being (capabilities, psychological functioning, culture and beliefs). Second, Internet may arguably have different effects on the distinct dimensions of well-being noted in the previous section: hedonic, evaluative and eudaimonic well-being. Third, since Internet includes a wide range of diverse applications, its impacts on human well-being will obviously depend on the specific type of application that we are considering. In this paper, we argue that - in spite of the large variety of mechanisms linking Internet use to well-being the main relevant effects can be grouped into four distinct categories.

1. Change in time use: Internet enables to carry out a given activity in a more efficient manner than this was carried out before, thus changing time use patterns and potentially freeing up time for other activities. Hence, Internet provides individuals with the opportunity to use increased available time for other well-being enhancing activities.

2. New activities: Internet makes it possible to undertake completely new activities that were previously not feasible, and that can have direct benefits for individuals' well-being in different domains of life, as well as by enhancing their capabilities and psychological functioning.

3. Access to information: Internet enables individuals to get access, process and archive information in a much more systematic and rapid manner than previously possible. This can increase both efficiency and quality in many fields of human life, and potentially have direct benefits to well-being.

4. Communication tools: Internet also makes it possible to use new or improved forms of remote (distance) communication, increasing the potential scope and intensity of social interactions, which is a crucial dimension of well-being.

The reason for highlighting these four mechanisms is that these are the four distinct types of effects that we have identified in the large number of papers that we have surveyed (see table 1 in previous section). Papers in different fields of research have typically focused on one of these 
effects only, and it is therefore useful to bring all the four channels together in an integrated typology.

It is important to point out that the four channels noted above do not necessarily identify positive effects, but they can equally well be used to investigate potential risks and negative effects. For instance, as it will be elaborated further in the next sections, the fact that Internet affects time use patterns may possibly lead to negative, instead of positive effects, if an individual is not able to spend the additional available time in well-being enhancing activities. Analogously, the diffusion of new Internet services may lead to risks of increasing economic inequalities between different categories of users and different social groups. Further, the increased access to information leads to well-known ethical questions related to privacy. Finally, the new tools of online communication can sometimes simply substitute ordinary face-to-face interactions and decrease the time that individuals devote to these, with possible negative effects on social capital. And they can also lead to greater isolation and social exclusion if they are not used in a sensible manner.

The new typology outlined in this section can be used to categorize the main relevant effects of Internet on well-being. The remainder of this paper will use this typology as a conceptual device to carry out our literature review, which is organized by discussing the effects of Internet in different domains of life (sec. 5) and in relation to different personal characteristics (sec. 6).

\section{Effects of Internet in different domains of life}

\subsection{Private Life}

The private life domain refers to the set of activities that human beings carry out in their spare time: social life and consumption activities.

\subsubsection{Social Life}

Social interactions in private life are rapidly changing due to the increasing use of mobile phones and the Internet. Most of the research initially focused on the intensity of Internet use, and has later shifted to focus more specifically on Social Networking Sites (SNS) such as Facebook (Burke et al., 2010; Manago et al., 2012; Wilson et al., 2012). 
Kraut (1998) examines what effects the Internet has on individual's social involvement and wellbeing. The study argues that greater use of the Internet leads to less communication with family members and declines in social circles. Nie (2001) finds that use of the Internet can reduce interpersonal interaction and communication, and Mesch (2001) points out that socially isolated adolescents are more likely to use the Internet often. Other works, such as McKenna and Bargh (2000) and Gross (2002: 88), argue that the Internet could indeed "serve distinct functions for socially anxious and lonely individuals", but that for most people the Internet in itself does not necessarily have an effect on well-being, it simply provides a new platform on which to operate. Overall, though, the majority of early studies on this topic indicated that use of the Internet could have negative impacts on social life and well-being, mostly due to the fact that online communication simply substitutes ordinary face-to-face interactions and decreases time that individuals devote to these (Franzen, 2003; Bruni and Stanca, 2008; Valkenburg \& Peter, 2009; Sabatini and Sarracino, 2017). However, other studies point out more uplifting results. Valkenburg and Peter (2009) argue that while the Internet was initially used for contact with strangers, it has later become a platform where people develop and cultivate their already existing relationships, and this has proven to be beneficial for social well-being. Kraut et al. (2002) also revisit their study of Internet use some years later, and find that the negative effects of the Internet on social life had dissipated and gradually turned into positive effects.

More recent research has shifted the focus to the effects of Social Networking Sites (SNS) on well-being. Ellison et al. (2007), Burke (2010), Manago et al. (2012), Oh et al. (2014) and Steinfield et al. (2008) study SNS and find that users of these sites have increased social capital, social support, sense of community and improved well-being. Most of the articles also discuss certain negative aspects associated with SNS use - such as increased narcissism, superficial relationships and increased stress - particularly if the platforms are used with high frequency and for excessive amounts of time.

In spite of the recent increasing interest in the use of social media, extant research on Internet effects on social life is still limited and fragmented on a variety of different topics. To systematize the insights from this research, we use the typology presented in section 4 to point out the four main channels through which Internet can affect well-being (see table 2). First, in social life, the Internet and SNS can affect time use patterns, and often save a substantial amount of time, e.g. by facilitating and managing social events online, thus contributing to develop 
interpersonal relationships. Kraut et al. (2002) argue that using the Internet increases face-to-face communication and helps develop relationships with people that are far away geographically. Koku et al. (2001) also point out that the Internet is most useful for facilitating and maintaining off-line relationships, and Zhao (2006) finds that those using the Internet for interpersonal contact usually have more social ties than those who do not. Overall, when used to save time by facilitating real world interactions, Internet may indeed have positive effects on well-being.

Second, Internet has fostered the development of a large number of new activities and services that are meant to facilitate new kinds of social interactions that were not previously possible. For example, in areas such as online dating (through mobile apps like Tinder, Happn and Melt), ICTs can use location data to find others in the area based on users' stated preferences and facilitate real world social interactions. This is also spreading to other kinds of social interactions, and can for instance happen through interactive gameplay that relies on augmented reality such as the mobile gaming platform Pokémon GO. This, if used effectively, could be positive for the development of social lives and expanding social circles through ICT use. However, there are clear pitfalls and risks such as misuse of these new services for illegal purposes, or unhealthy excessive use.

Third, Internet also enables an unprecedented access to information about other users in personal networks through SNS. This may strengthen social capital and relationships. SNS makes it simple to keep track of existing acquaintances, and easier to have access to information relevant to one's social life. However, the greater access to information can also present new risks as individuals now have the possibility to compare themselves to many other users worldwide, and hence create world-wide (rather than local) reference groups. Kraut et al. (2002) also state that one of the most common uses of the Internet is for accessing information, and argue that heavy Internet users actually know less about their local area and community, as the Internet makes international news just as accessible as the local news. Through SNS, reference groups are now expanding to include a wider social circle as well as the world itself. This could potentially be negative or positive for a person's well-being depending on their social standing. This is also relevant for other domains of life, such as individuals' relative income (see section 5.2.2 below). However, as noted above, the most influential and pervasive impact of Internet on social life is likely through communication patterns. Vast amounts of communication now go through mobile phones, SNS, instant messaging and image/video applications. As interpersonal relationships are 
some of the strongest predictors of well-being, this change in behavior is of particular interest for the relationship between social life and well-being (Kahneman et al., 1999). Gross (2002) argues that online communication can be used either to develop already existing off-line relationships, but also to avoid feelings of loneliness, and that the content of the communication between participants plays a major role in determining the effect on well-being. If the interaction is positive in nature, so is likely the effect. But Internet can also open up for negative interactions such as cyberbullying and online harassment (Smith et al., 2008). Furthermore, online communication and SNS use can worsen the quality of face-to-face interactions, thus leading to another possible negative impact on well-being (Lee et al., 2011; Helliwell and Huang, 2013; Mc Dool, 2016; Rotondi et al., 2016).

\subsubsection{Consumption}

The goods and services we consume in our daily lives affect our well-being by satisficing our basic needs and preferences. Individual consumption patterns have changed radically due to Internet technologies, and extant research has discussed both positive and negative effects of these for consumption activities (Kasser, 2004; Pea, 2012; Sirgy et al., 2007). Much of this literature distinguishes between passive or active consumption, and between regular (moderate) and excessive consumption. Passive consumption is usually associated with TV or Internet surfing (viewing content, playing games), while active consumption or active leisure is associated with the use of computers for creative tasks or active participation in joint activities. Further, regular (moderate) use of Internet is typically found to have positive (or at least not negative) effects on well-being, while an excessive and uncontrolled use can lead to risks and negative impacts.

For instance, Frey et al. (2007) point out that people who are considered heavy consumers of television report lower well-being and higher anxiety levels, and Hamer et al. (2010) state that both the physical and mental well-being of those watching TV more than four hours a day is “poor" (Hamer et al., 2010, 376). Pea (2012) and Leung and Lee (2005) find that too much

passive or excessive consumption of new media technologies is negative for well-being, and Kasser (2004) argues that when people organize their lives around a consumer culture their wellbeing is likely to be diminished. 
On the other hand, Edginton et al. (1995) point to a positive relationship between well-being and active leisure, particularly for tasks which match a person's skill with the challenge of the leisure activity. Pea (2012), in a study of young people's use of media, argues that productive and creative uses of ICTs can be positive for well-being, and Leung and Lee (2005) find that using the Internet and new media technologies for leisure can have positive impacts on well-being.

We now systematize these previous insights by using the typology outlined in section 3 (see table 2). First, the time-use dimension is relevant for consumption activities. The fact that activities such as e-commerce and online banking services are becoming widespread can save consumers substantial amounts of time. This time can instead be used for leisure or other activities perceived to be more fulfilling to the individual (Edginton et al., 1995). However, it should be noted that the additional time now available will not necessarily be used for fulfilling activities. Further, the time-saving function of ICTs may also possibly lead to a faster pace of hedonic adaptation, namely the time it takes for individuals to adapt to the pleasure of a new consumption item and return to their baseline level of well-being. By saving more time, and consuming more, people are arguably adapting more quickly, shortening their average adaptation times, and weakening their capacity to feel satisfied with the material wealth and consumption level they can afford.

Second, since Internet has enabled the introduction of brand new services, individuals can now enjoy new experiences and create new consumer patterns. Among many other examples, we can for instance refer to new collaborative consumption services such as ridesharing (Uber), house sharing (Airbnb) or crowdfunding (Kickstarter). Research shows that the actual enjoyment of these new activities is a an important explanatory factor for individuals motivation to use collaborative consumption services (Hamari et al., 2015). When consumers enjoy new services more, this will foster their hedonic well-being.

Third, by having access to more relevant information on consumption items and prices, consumers can now research online before purchasing, improving the satisfaction level with the goods and services they purchase (GE Capital, 2013). O'Connor (2008) presents a case study of the online review site TripAdvisor, and shows that consumers use this travel review site to find the best possible consumer experience and rate the ones they are most satisfied with. As consumer ratings will influence the profitability of a business more than before, this makes it 
more likely for service providers to value the consumers' well-being highly (O'Connor, 2008). This in turn improves these services and fosters consumers' hedonic well-being.

Fourth, by using Internet as an online communication tool, consumers can also have more efficient and more pleasant interactions with their product and service providers. These interactions with customer service can affect their customer satisfaction accordingly (Innis \& La Londe, 1994). This can also have potential negative effects, though, as more and more companies use computer generated responses to interact with their customers. Since negative effects from Internet use is related to solitary use or by not using it to interact with other human beings, it would be reasonable to expect that these new forms of clients-providers interactions can potentially have negative effects on well-being as well (Kraut et al., 1998).

\subsection{Work life}

Next we discuss how Internet affects work life through the quality of work and its impacts on relative income.

\subsubsection{Work quality}

There is an extensive literature on the effects of work quality on well-being. This has mostly been focused on employment vs. unemployment status, the effect of work on general life wellbeing, the work/family relationship, and how well-being impacts employee's performance (Fisher, 2010; Helliwell \& Huang, 2010; Veenhoven, 1984; Warr, 1999). Interestingly, however, despite the fact that many if not most work places have changed due to Internet technologies in the last decades, there is little research on the effects of these on workers' well-being (Salanova et al., 2004; Castellacci and Viñas-Bardolet, 2017).

Focusing on the limited research on Internet and quality of work, results appear to be mixed and inconclusive. Brooks (2015) shows that social media for personal use leads to lower performance of work-related tasks and lower levels of well-being. On the other hand, Moqbel et al. (2013) find that use of SNS at work increases organizational commitment and job satisfaction. Venkatesh and Speier (1999) study how ICT training influences mood and ultimately use of the technology. They argue that having a negative attitude towards ICTs has a long-term effect on their use. Salanova et al. (2004), in another study on ICT implementation, point out particularly 
positive effects on job satisfaction in companies that implement new digital technologies for the first time, although employees respond differently to the introduction of new IT systems within the company (Bala and Venkatesh, 2016). Seo et al. (2015) argue that Internet influences workers' creativity and well-being. Overall, the effects are variegated and diverse. On the whole, however, it seems that if ICTs and Internet applications are implemented with care and used for enhancing creativity and efficiency at work, their presence can positively influence well-being (Salanova et al., 2004; Seo et al., 2015; Venkatesh \& Speier, 1999).

Using again the typology put forward in section 4, we seek to systematize this research by pointing out four distinct channels through which Internet use can affect work life satisfaction (see table 2). First, regarding the change in time use, a plethora of tasks that were previously done manually are now automated: this can save time and avoid physically straining labor and repetitive tasks. Employees in occupations with high demands and little control over their working tasks typically report lower job satisfaction than others (Van der Doef \& Maes, 1999). Some of the occupations that have high demands and little personal control are also the kinds of occupations that typically can be automated and made more flexible by digital technologies (Golden and Veiga, 2005). Automation could then lead to time- and energy-saving for some workers and hence improved well-being. However, automation of tasks also makes certain jobs rapidly obsolete, while raising the skill and education level that is required to perform the new tasks. Large scale automation of jobs can therefore potentially also have negative effects on wellbeing by increasing unemployment (Dolan et al., 2008).

Second, Internet has led to the creation and development of brand new working activities and tasks that necessitate new high-skilled professions. This is particularly so within the IT industry, where there are many new occupations such as designers, developers and coders. These positions often require specific skills, provide physical security and some opportunity for personal control, all factors that are positive for well-being at work (Warr, 1999: 396). However, these new occupations related to ICTs production and management also tend to replace other occupations, thereby increasing unemployment (or worsening working conditions) in other sectors of the economy (Martin and Omrani, 2015; Castellacci \& Viñas-Bardolet, 2017).

Third, Internet provides improved access to, and sharing of, information through internal platforms at work as well as worldwide networks of knowledge. Utilizing Intranet at a workplace can spur more efficient sharing of internal knowledge, and this has been found to positively 
affect knowledge sharing within a company (Hendriks, 1999). As many employees also take advantage of worldwide networks of knowledge such as scientific journals, online forums and encyclopedias, these can contribute to improving their skill level, work quality, and in turn wellbeing.

Fourth, Internet has made it possible to create new communication tools that are now commonly used in most work places, such as email or internal communication platforms (e.g. "Facebook at Work"). These new communication tools allow for rapid sharing of specific job-related information between employees that can greatly improve the quality of work, as well as its efficiency and productivity. Pincus (1986) and Warr (1999) point out that communication patterns at work are related to well-being of employees, and ICTs likely affect this relationship by creating new ways to communicate. Others argue that online communication tools at work can negatively affect the balance between work and private life, by keeping employees online at all times regardless of their physical location, even in their spare time (Boswell \& OlsonBuchanan, 2007; Chesley, 2005). Some recent studies also show that the use of SNS at work can have negative effects on productivity, which can in turn have negative effects on the workers' morale and job satisfaction (Brooks, 2015; Jacobsen \& Forste, 2011). In sum, using Internet communication tools at work has potentially positive impacts on well-being, but there are also dangers related to the blurring lines between work and leisure time.

\subsubsection{Relative income}

The spread of Internet throughout workplaces can also have wide reaching effects on individuals' income. Richard Easterlin originally pointed out that economic growth in itself does not necessarily increase well-being, and argued that the latter is actually dependent on relative income (Easterlin, 1974, 1995; Layard, 2011). Easterlin also argued that there is a satiation point, or a plateau, at which income and well-being do no longer correlate. Our interest here is to reflect on how the so-called Easterlin paradox may be related to Internet use.

Clark and Senik (2010) show that those with no Internet access in general attach less importance to income comparison than those who do have access. Further, Lohmann (2015) indicates that those who use the Internet regularly are less satisfied when their income increases compared to those who do not use it regularly. This could be explained by two related mechanisms. One is raising material aspirations due to greater exposure to affluence ideals (Bruni and Stanca, 2006; 
Hyll and Schneider, 2013; Sabatini and Sarracino, 2015). The other is that individuals with regular Internet access more often compare themselves with other online users, and this in turn will lead to an increase (decrease) in well-being for those groups or individuals that have on average higher (lower) relative income. Clark and Senik (2010) suggest that in a society where there is a greater prevalence of information in media and other platforms about other people's lifestyles, there can be a negative effect on well-being as individuals often compare themselves to people with more extravagant lifestyles. Overall, these previous insights suggest the existence of possible negative links between Internet use, income and well-being. However, there are arguably other ways in which Internet technologies can influence income and well-being that have not been investigated yet in extant research.

By using our typology, we point out four different channels through which Internet can affect relative income and individuals' perception of it (see table 2). First, as noted above, a major change in working life is the change in time use patterns related to the automation of previous manual tasks, which can affect the income of both high and low skilled jobs. Automation raises the level of competence required by some employees, as their jobs become focused on more complex tasks, and this will in turn positively affect their relative income. As a simple illustration, consider the changing tasks of a bank teller - from originally being responsible for accepting, counting and registering money from customers, to now advising customers on financial investments and assisting with online transactions. This change demands a higher level of competence and a different set of skills that are compensated by a higher salary. Correspondingly, task automation makes other jobs obsolete, which will lead to a decrease in relative income for some social groups and some sectors with lower training and skill levels.

Second, Internet can have a massive impact on the distribution of income as new ICT services disrupt existing industries and lead to structural change. For example, in new collaborative consumption services, companies such as Uber and Airbnb are changing the entire taxi and hotel industry, creating and removing jobs in ways that was not possible to imagine before. This can of course be negative for the workers in some of the obsolete occupations, such as the ordinary taxi driver. And in the case of Airbnb, there is no longer any need for a receptionist, as people rent out their own rooms and apartments online. At the same time, these new services provide new opportunities for those in the workforce participating in the new sharing economy services. 
Third, the growing access to online information about others is relevant in the light of the recent debate about the relevance of relative and absolute income for well-being. While Easterlin

originally pointed out the importance of relative income, Sacks (2012) finds that absolute income plays a major role for well-being, and argues that there does not exist any satiation point as Easterlin contended. Due to Internet use, the differences between absolute and relative income may become less important than previously thought. Deaton (2008) and Diener (2012) argue that due to the increase of information access through television, media and the Internet, these differences are shrinking. While people used to compare themselves to their neighbors and coworkers, they now have the possibility to compare themselves to a "global standard" of living (Deaton, 2008: 70). In this sense, relative and absolute income do now differ less significantly than it was the case in the past, since people can compare to others based on more complete information about what their absolute income is and makes it possible to purchase. One interesting example is how countries such as Norway provide online public tax records, which make citizens' income publicly available information through an online portal. This makes it possible for individuals to compare themselves to anyone else in their social circle, workplace or even to strangers.

Fourth, Internet can function as sophisticated communication tools for businesses and between customers and businesses, creating higher revenues (and higher relative profits and income) for those companies that are better able to exploit these new technological opportunities. Internal networks of information and communication that make it easier to share knowledge, strategies and best practices across business units and between employees may represent a factor of competitive advantage for an organization, leading to higher profits (Hendriks, 1999). Further, businesses can use online marketing tools to more efficiently reach specific customers, in turn earning more profits on customers who want their product or service. For example, by reaching out to customers with personalized offers based on the online revealed customers' preferences can generate higher revenues as well as be more rewarding for the employees offering better products and services than previously.

\subsection{External environment}

Beyond private life and work life, another relevant dimension of daily life is the external environment people live in, which has previously been pointed out as another crucial determinant 
of well-being (Diener, 2012; Helliwell \& Putnam, 2004). By external environment we mean both the "physical environment", such as the climate, the urban or rural setting in which individuals live, and the "socio-institutional environment", such as governance structures, social trust, safety and security.

\subsubsection{Physical environment}

The physical environment has extensively been investigated in well-being studies (Blomquist et al., 1988; Moro et al., 2008; Prescott-Allen, 2001; Schmitt, 2013; Zhang et al., 2015). The physical environment can affect well-being through for instance climate, air quality, pollution and weather conditions (Frijters \& Van Praag, 1998; Schmitt, 2013; Zhang et al., 2015). These characteristics can have immediate effects on hedonic well-being. Further, a different channel linking the environmental dimension to individual well-being is that awareness of environmental concerns, active engagement and participation in environmental campaigns can strengthen interest and feelings of belonging to the surrounding community, with positive impacts on eudaimonic well-being. There is, however, very limited literature on how these relationships can be affected by Internet technologies.

Craglia et al. (2004) argue that traditional measures of quality of life need to be supplemented with dimensions reflecting the emerging digital cities that are in large part shaped by ICTs. The study points out however that it is hard to find appropriate definitions and measurements of these aspects. GhaffarianHoseini et al. (2013) also discuss how integrated ICT technologies in urban settings could enhance the quality of life in cities as well as improve sustainability.

To advance our understanding of the links between Internet and well-being through the physical environment, it is important again to distinguish four distinct channels (see table 2). First, Internet applications provide new digital infrastructures in cities where transportation and other public services can be digitalized, increasing efficiency, reliability and comfort of these services, and leading to time saving for the individuals using these services (Craglia et al., 2004).

Second, digital technologies permit the introduction of new products and services that can have positive environmental benefits. An important example is the emergence of energy informatics, which will in the future foster the development of sensors of artificial intelligence and machine learning, creating smart energy efficient cities, houses and industries. These will be used to save energy, and in other contexts even to control pollution, predict earthquakes and improve 
recycling activities (Arnfalk, 1999; Wu et al., 2014). A simple illustration is the thermometer that saves energy by learning the habits of the user, and which is well-being enhancing for both the user and the climate.

Third, as Internet provides greater and more systematic access to information, they can be used to more efficiently gather data and monitor climate and the environment. For example, by using services such as the online Real-time Air Quality Index, it is easy for citizens to get information about the air quality where they live, and to have an informed opinion of their surroundings (World Air Quality, 2016). This may be positive for eudaimonic well-being in the sense that this new information provides improved opportunities to participate and change the status quo (Graham \& Nikolova, 2013). However, it could also be argued that people living in areas of poor air quality could more easily compare their environmental conditions to the rest of the world and hence experience reduced well-being as a result of this newly available information (which would not have been available were it not for online information).

Fourth, Internet can function as communication tool to foster awareness of environmentally friendly activities and groups, affecting the environment as well as individual well-being. Studies have shown a positive link between uses of SNS, political participation and activism (Valenzuela, 2013). Others have questioned whether political actions pledged through the Internet or SNS actually translates into political action, as this usually requires little effort, such as signing an online petition or joining a campaign group on a social media website. This has been dubbed 'slacktivism', indicating the online participation to a cause with as little effort as possible. Most evidence, however, seems to indicate that there is a positive link between online participation and activism, and that for those merely participating online, it can have still have a positive effect on others in their network (Christensen, 2011; Rotman et al., 2011; Valenzuela, 2013). This suggests a positive effect on eudaimonic well-being for the participants in environmental friendly groups.

\subsubsection{Socio-institutional environment}

The socio-institutional environment that characterizes our society, such as governance structures, trust in other citizens, safety and security is highly relevant for well-being (Dolan et al., 2008; Helliwell \& Huang, 2006). Frey and Stutzer (1999) show that citizens who are active in the democratic process report higher well-being levels than those who are not, and Helliwell (2006) 
and Helliwell and Huang (2006) find that the ability of governments to provide a trustworthy environment is paramount for well-being, particularly in those countries with poor governance and low absolute income. Internet applications that improve in some way the socio-institutional environment can positively affect well-being. Ganju et al. (2015) point out that greater governmental emphasis on ICTs leads to more Internet use in a country, and that increased use improves citizens' well-being. Therefore, if governments are committed to providing more online public services, this will likely increase well-being. On the other hand, Internet can also be used for criminal activities. For instance, Bhuller et al. (2013) present a thorough analysis of the causal effects of the introduction of broadband Internet on the increase in sex crime.

Overall, Internet applications in the socio-institutional environment can affect well-being through four distinct channels (see table 2). First, moving certain public services online can save citizens' time and diminish the effort previously allocated to monotonous (and sometimes stressful) tasks. This may increase hedonic well-being, and by freeing up time for more fulfilling activities could increase eudaimonic well-being as well. Carter and Bélanger (2005) study egovernment adoption of an online tax system and an online system for car license renewal and show that having Internet-based services that are easy to use, trustworthy and compatible with existing uses is a significant predictor of citizens' intention to use governmental e-services. When these criteria are met, it is likely that citizens would rather use online services than traditional ones, and in turn save time, cost and enjoy the experience more.

Second, Internet often leads to the introduction of brand new activities, such as big data applications, which can put together existing data in new ways and ensure better public services, as well as increased public safety through surveillance programs. For example, in several countries there are experiments with using big data programs to predict where crime will happen (Easton, 2016). Bogomolov et al. (2014) use aggregated human behavioral data from mobile networks to predict whether an area in London would be a hotspot for crime, and experimental results indicate an accuracy of almost $70 \%$. However, while trust and reduced crime are linked to improved well-being among citizens, this also presents major ethical challenges and potential pitfalls that can have negative outcomes for well-being. These programs can potentially be misused by governments and corporations to hamper personal growth or freedom of expression amongst the population. The effects on well-being will therefore rely on ethical and responsible 
development of these new technologies, as discussed extensively in Von Schomberg's (2011) study on how create responsible research and innovation in the field of ICTs.

Third, through increased access to information, individuals can have better information about their society, increasing their sense of belonging to their community as well as their safety. For example, in India, citizens can register where they have been asked to bribe governmental officers, and their reports are sent to government officials and the media to increase transparency and the quality of life among citizens, who can learn where to go to avoid having to bribe someone (Ramanna \& Tahilyani, 2012). This can decrease the spread of bribery and corruption, increase trust and thus spur well-being. But this could potentially have negative effects as well, as it makes it clear to citizens how widespread corruption is in different areas of a country, arguably decreasing the perceived well-being of citizens living in areas with extensive corruption. As a further example, an increasing number of police departments around the world are also using the SNS Twitter to send out information directly to the public in real time, increasing efficiency and trust among the public. Currently, this new tool is mostly used as an addition to existing means of communication, but there are many opportunities to increase public knowledge and societal trust according to recent research (Crump, 2011). On the other hand, the increased access to information also raises the important question of the reliability of online sources, and the extent to which individuals are affected by 'fake news' and other non-reliable knowledge sources that proliferate through the Internet.

Fourth, Internet-based communication tools enable more rapid and transparent interactions between citizens and public authorities, through e.g. online portals for e-government services, or by improving civic engagement among citizens. Park et al. (2009) point out that social trust can significantly predict civic engagement among SNS users, and argue that SNS can be a powerful tool for drawing young adults' attention to societal concerns and uniting them as active participants in society. Frey and Stutzer (1999) find that perceived ease of use, compatibility and trustworthiness are significant predictors of citizens' intention to use an e-government service, and that as these tools can function as a way to garner more civic participation they can increase citizens' sense of belonging and hence their eudaimonic well-being.

\section{< Table 2 here >}




\section{Effects of Internet through personal characteristics}

We define personal characteristics as all those individual traits that are inherently part of the psychological functioning of individuals, and that shape how each person perceives, feels and constructs her everyday life and feelings of well-being. Specifically, in line with the literature, we consider three distinct dimensions: (1) psychological functioning, (2) capabilities (particularly health and education), and (3) culture and beliefs.

We argue that Internet can have both indirect and direct effects on well-being by affecting personal characteristics. In this section, we will focus on the direct effects, which are those channels through which Internet directly affects individuals' personal characteristics and feelings of well-being. The next section will then point to some important indirect effects, i.e. how personal characteristics mediate the relationship between Internet and well-being in different domains of life.

\subsection{Psychological functioning}

In a series of influential articles, Ryff and collaborators argue that a person's hedonic and evaluative well-being does not sufficiently account for her positive functioning, and analyze a series of factors that can shape eudaimonic well-being, which is arguably more relevant to assess emotional and physical health. Important dimensions of this are self-acceptance, positive relations with others, autonomy, environmental mastery, purpose in life, and personal growth (Ryff, 1989; Ryff \& Keyes, 1995; Ryff \& Singer, 1998, 2008).

Psychological research on eudaimonic well-being has investigated a variety of relevant factors, and only recently begun to consider how Internet use shapes individuals psychological functioning. In the field of psychology and human computer interaction, recent research focused in particular on how SNS affect people's psychological well-being. Burke (2010) and Oh et al. (2014) find that supportive interactions through social networks are associated with more bonding, positive affect and increased perceived social support. Li et al. (2014) argue that psychological needs satisfied through online communication can induce self-esteem, and Steinfield et al. (2008) point out that individuals with low self-esteem gain more from the use of SNS than those with higher self-esteem. These findings suggest that SNS use can be positive for important aspects of psychological well-being such as self-esteem and relations to others. 
However, Burke (2010) shows that users who consume more content than others on SNSs typically report reduced social capital and increased loneliness, and Li et al. (2014) report that the psychological needs satisfied by communicating online can additionally influence individuals' shyness in a negative manner, and that this could in turn decrease their self-esteem and result in lower well-being. Caplan (2003) points out that people who suffer from depression and loneliness are more likely than psychologically healthy people to develop a preference for online social interaction, and argues that the latter can for some people be less threatening and more rewarding than ordinary face-to-face interactions. Yet, over time, people who prefer online interactions may use this excessively and compulsively and thus increase the risks of negative effects such as depression and loneliness. Winter et al. (2014), in a study of status updates on the SNS Facebook, argue that those with higher degrees of narcissism also prove to post deeper selfdisclosures and more self-promotional material than others. This could mean that the platform of SNS lends itself to narcissistic tendencies, and that narcissists' inflated image of themselves may be more easily detected by others within an SNS, in turn decreasing their social status. These findings indicate that SNS can be negative for individuals that suffer from psychological distress (e.g. loneliness or depression), or people with narcissistic personalities, as these symptoms can be amplified by using social networking sites.

An important dimension that may affect the relationship between Internet use and psychological well-being is age. Some studies have focused on different age groups to get a better understanding of the specific opportunities and challenges that Internet provides for individuals at different life stages. First, focusing on children, Jackson et al. (2008) find a positive correlation between Internet use and psychological well-being, and a negative correlation with video games use, whereas McDool et al. (2016) point out the negative effects that social media use may have for children. Second, focusing on adolescents, Gross et al. (2002) find a positive effect of online interactions when these are with peers and friends rather than with strangers. Valkenburg and Peter (2009) survey studies of ICT effects for adolescents, discussing the reasons why it is more common to observe positive effects in more recent studies. Third, some papers focus on Internet use of older adults. Chen and Persson (2002) find that Internet use has stronger effects on well-being for older than for younger adults, but this result is not supported by the literature review on this topic carried out by Dickinson and Gregor (2006). Ford and Ford (2009) argue that Internet use may have beneficial effects on depression for older adults, due to 
the possibilities it gives to strengthen and maintain communication and social ties, as well as to access useful health-related information. In a cross-country econometric investigation, Lelkes (2013) also points out a positive relationship between Internet use and well-being for elderly people. In summary, the studies briefly noted here point out that age is a key factor affecting the relationship between Internet and psychological well-being.

Overall, research on the effects of Internet use on psychological functioning has in large part been focused on SNS platforms, which is natural given the high popularity and rapid diffusion of these in recent years. To broaden up the focus of this research and consider other possible channels, we use again our typology (see table 3). First, by using Internet tools to change their time use patterns, individuals can have access and experience rewarding activities more efficiently and more easily than before. For example, as one can now book and arrange travel online in an easy and efficient manner, more people have the opportunity to travel, learn about other cultures and enjoy different experiences potentially leading to personal growth and a broader sense of purpose in life.

Second, new online services that are directly aimed at lifestyle changes and personal growth can indeed foster eudaimonic well-being. There is a growing market of particularly mobile applications meant to decrease stress, help meditate, increase well-being or focus on specific aspects of mental well-being. All these can improve the psychological well-being of individuals through increased self-acceptance and spur new habits for personal growth. For instance, mobile phones are now often used for applications for meditation or mindfulness, which Brown and Ryan (2003) argue can predict positive emotional states and be positive for psychological functioning. Also, by using creative applications that were not previously available, more people can express their feelings through different artistic outlets such as in photo, music and video editing, increasing their purpose in life and experiencing personal growth.

Third, the increasing access to information through Internet can have both positive and negative consequences for eudaimonic well-being. In channels such as news sites, SNS, YouTube, encyclopedias and online courses, individuals can broaden their knowledge bases considerably, learn new skills and in turn experience personal growth and increased eudaimonic well-being. However, these same channels can sometimes present overwhelming information, making individuals compare themselves to the best in the world, rather than the best in the neighborhood, 
potentially negatively influencing their feelings of environmental mastery and hence their eudaimonic well-being.

Fourth, and distinctively important, new communication tools can affect psychological functioning. As noted above, the Internet and SNS are main channels of influence, as much of social interactions have moved online in recent years. Research finds that the effect of online communication on well-being will often depend on whether the content of what is being communicated is perceived to be positive or negative, as well as whether the use of the SNS is regular and moderate or if it is excessive (Bargh, 2004). This point is similar to the one made in section 5.1.2 on the use of Internet for consumption activities. McKenna and Bargh (2000) argue that like the telephone before it, the Internet in itself is not the main cause of anything; it is but a new platform for these interpersonal relationships to develop. Rather, they argue that social interactions and relationships may be formed differently online than in regular face-to-face interaction. They show that people online do have more anonymity and greater control over time and pace of interactions with others, but that the main effect on an individual's eudaimonic wellbeing would stem from the interactions with others. Those using SNS for regular communication with positive interactions can experience more perceived social support, sense of community and increased social capital (Manago et al., 2012; Oh et al., 2014; Steinfield et al., 2008). However, using online communication excessively or for negative interactions can present risks for wellbeing (Burke, 2010; Caplan, 2003; Kasser, 2004; Mitchell et al., 2011). Though online communication is dependent on the kind of interaction and type of use, more research is required to study what different kinds of Internet services do to psychological well-being.

\subsection{Capabilities (health and education)}

Sen $(1985,1993)$ originally pointed out the role of capabilities for human development and wellbeing. Some of the key capability dimensions are health and education, as well as other aspects such as self-respect and social integration that have already been discussed in previous sections of the paper. We focus here on online applications for health and educational purposes and their direct effects on well-being.

Through Internet technologies, the health sector has new ways of treating patients, there are greater opportunities for individuals to keep track of their own health, and there are increased opportunities to communicate with others for elderly and those with lowered functionality. 
Research on ICTs, health and well-being has found important positive relationships particularly for elderly patients, but the results for younger patients are still mixed and inconclusive.

Orpwood et al. (2007) follow the process of designing digital technology meant to support quality of life of patients with dementia. White et al. (1999), in a review of Internet use for the elderly, show that use of the Internet can help avoid social isolation and improve well-being. However, when it comes to younger age groups, results are often found to be negative. Mathers et al. (2009), in a study of adolescents' time using electronic media, report that higher overall usage was associated with poorer health and well-being, particularly in regards to time spent playing video games. Cotten (2008) points out that there could be health risks to using mobile phones, and that excessive Internet use by students can have negative impacts on their health. Overall, elderly people appear to be able to reap benefits from ICTs applications mostly in care and for communication purposes, while for younger age groups there are questions of unhealthy and excessive use, and potential health risks in using mobile phones frequently.

In addition to health, the other important aspect of human capabilities that we highlight here is education. Internet can positively affect well-being when it is used to improve the quality of educational services and increase the amount and organization of available knowledge - e.g. through online platforms for learning. However, ICT-based devices can sometimes present risks and induce negative effects if students' excessive use of SNS and mobile phones interferes with the due learning and cognition processes. Purcell et al. (2013) argue that the Internet has a major impact on teachers' ability to access content, resources, and materials for teaching, as well as a major impact on students learning habits, particularly by using search engines such as Google. The related effects are arguably positive. However, while schools often have the digital tools to support the students, not all students have these tools available at home, and these differences in digital access may lead to a digital divide between the have and have-nots, potentially negative for the have-not students and their cognitive development and well-being. Another potential side effect for students is excessive cell phone usage, which is noted to have negative consequences for students' academic performance, mental health as well as their well-being (Li and Barkley, 2015). Internet applications can have positive effects on capabilities in terms of increased available knowledge and digitalized teaching methods, but students' use can also have negative effects on their mental health and well-being. 
In sum, the range of potentially relevant effects on capabilities such as health and education is broad. To systematize this variety, we make use of our typology (see table 3). First, Internet can increase the efficiency of public health and educational services, leading to quality improvements and substantial time saving effects for the individual groups in question (e.g. patients and students). Examples include rapid and easy access to digital health records available for all medical offices, and the use of online educational platforms, or e-learning platforms, such as "itslearning" and "moodle".

Second, Internet innovations in these fields have clear benefits for well-being. The health sector presents abundant illustrations. ICTs in organization, equipment, and information sharing have substantially transformed the health sector, and Suomi (2000) argues that it has turned from a handicraft industry to knowledge industry. This can create better health services and improve patients' health and well-being. New apps also provide people with the opportunity to monitor their own health through gadgets such as wearables or embedded in mobile phones. These can remind users to walk more often, monitor sleeping patterns, and in effect "nudge" individuals towards better health. Analogously, the educational field benefits from similar tools that help students concentrate, create regimes and learning routines and measure progress in ways that were previously not available.

Third, the Internet provides increased access to information that can be useful for educational and health purposes. For health, there is a lot of information available online through simple search strings or websites such as WebMD. Andreassen et al. (2007) show that $71 \%$ of individuals in their sample use the Internet for health purposes, e.g. for finding information, deciding whether to see a doctor or as a follow up to traditional doctor appointments. Findings indicated that more people were reassured by what they found online than people experiencing feelings of anxiety. Though this can certainly improve well-being by providing quick answers to health issues, there are potential pitfalls for people who already have health anxieties and use the Internet without the due caution and attention to the source. In education, Purcell et al. (2013) report that use of the Internet and particularly search engines have a major impact on teaching, mostly positive. However, over $80 \%$ of the sample also argues that the amount of information that is available for students is "overwhelming”, having potential negative impact on the students' learning and cognition processes. There are also new educational communities: online course platforms such as the Kahn Academy and Coursera provide videos and interactive exercises to 
learn new skills from teachers and academics around the world for little or no cost, potentially increasing educational capabilities and well-being.

Fourth, using Internet as a communication tool in health and education can have important effects on well-being. To illustrate, elderly people with health issues who use the Internet to communicate with friends and family can improve their health, well-being and avoid social isolation (Bobillier Chaumon et al., 2014; White et al., 1999). In education, teachers find it easier to communicate with students through online platforms, potentially increasing the quality of education and well-being of the students (Purcell et al., 2013). Here, there is arguably a large untapped potential, as students are more active in utilizing opportunities in SNS for informal learning and organizing activities than faculty members are (Lampe et al., 2011; Roblyer et al., 2010). However, this can also lead to more student inefficiency as Madge et al. (2009) find that SNS are still mostly social and informal platforms, not yet designed or used as formal learning platforms.

\subsection{Culture and beliefs}

People's cultural contexts and belief systems are obviously important to shape individuals' perceptions about the experiences they live, and hence what they think and report about their own life status (evaluative well-being). Oishi et al. (1999), Suh et al. (1998) and Diener et al. (2003) point out differences in well-being between collectivistic and individualistic cultures. In individualistic countries, autonomy and emotions are more important elements for well-being, while in collectivistic countries, cultural norms and family life are regarded as more important values. For instance, Asian people are generally found to be happier when focused on doing something which will help them to achieve long term goals such as career or family life, while Westerners report higher levels of satisfaction and subjective well-being when doing something they enjoy in the moment (Asakawa \& Csikszentmihalyi, 1998). Well-being is also affected by religious beliefs, and individuals with strong religious beliefs report higher levels of life satisfaction and fewer negative psychosocial consequences of traumatic life events (Ellison, 1991). Little research has, however, focused on how these relationships between culture, beliefs and well-being are affected by the Internet.

In the absence of relevant research on this question, we use our typology to outline four distinct mechanisms (see table 3). First, the use of Internet and SNS to organize and spread information 
about cultural, political and religious events can now be done in a more effective and more rapid manner than before, and this may boost interest and foster participation to these events. Consequently, since Internet can automate previous manual tasks related to these activities, people now have more time to pursue and experience cultural and religious activities with possible positive impacts on eudaimonic well-being.

Second, as noted earlier, new online services, and particularly SNS, may provide human beings with new opportunities that were previously not available, but these can also induce certain aspects of psychological functioning known to be negative for well-being. Feelings such as narcissism, self-disclosure and living a more self-centered lifestyle can be exacerbated by online activities such SNS, playing video games or posting "selfies" (Ko, 2009; Manago et al., 2012; Sorokowski et al., 2015; Wei \& Leung, 1998; Winter et al., 2014). These are all traits that are typically more in line with an individualistic culture as it is mostly present in Western countries, where much of these online services are developed. SNS can induce a belief in autonomy and personal emotions over family life and cultural norms, which in effect can skew the population towards the adoption of a more individualistic culture.

Third, it is reasonable to think that the vast amounts of information that is now available online could potentially lead to a reduction of the gap between cultures and beliefs around the world. As previously noted, the use of SNS and online media may broaden the scope of the relevant reference groups of individuals from local neighbors to other individuals elsewhere in the world (Deaton, 2008; Diener, 2012). This could reduce the differences in perceived well-being between people in countries characterized by individualistic and collectivistic cultures, creating a more homogenous global culture. With rising secularization in Western societies where the spread of ICT is more rapid, one could also argue that increased spread of information may lead to weaken the relevance of religious beliefs. Armfield and Holbert (2003) point to a negative relation between religiosity and Internet use. By contrast, Kluver and Cheong (2007) argue that various religious communities are already embracing the Internet as part of their contemporary religious mission and strategy for continued growth. This shows again the diverse effects that Internet can have.

Fourth, also by using communication tools such as mobile phones, SNS and video conferencing, we may expect the differences between cultures to reduce. A major aspect of the globalization of culture is that it provides possibilities to communicate across the globe instantly, as well as 
consuming content from other cultures. Kramer et al. (2014) point out that emotional contagion can spread through SNS, since the content that individuals see and the type of communication they experience can affect their mood. As more and more individuals have online contacts with diverse people from a span of cultures in their SNS, it is likely that well-being perceived by individuals in a given country will be increasingly affected by other online users around the world. However, this also presents some important risks. Mass emotional contagion can potentially be driven by the spread of fake news and/or by demagogic use of the Internet, which may thus expose users to external manipulation.

\section{< Table 3 here >}

\section{A summary theoretical framework}

We will now summarize the key points of this analysis and outline the overall framework that the previous discussion leads to. A synthetic view of our framework is depicted in the diagram in figure 1. The diagram shows the main relationships between Internet use in different domains of life (private, working life, surrounding environment), personal characteristics (capabilities, psychological functioning, culture and beliefs) and well-being. ${ }^{3}$ These relationships can be summarized by means of three general propositions.

\section{$<$ Figure 1 here >}

\section{Proposition 1: New opportunities and positive effects.}

Internet creates new formidable opportunities for human beings and have a set of important effects on well-being. Although these effects are diverse and span a wide array of human activities, we have in the previous sections argued that it is useful to distinguish four different

\footnotetext{
${ }^{3}$ The diagram in figure 1 presents a set of unidirectional arrows going from the domains of life variables to wellbeing, as this is the main direction of causality that is investigated in the empirical literature that has been surveyed in this paper (see overview in table 1). However, it is important to acknowledge that some of these directional may also be bidirectional, since improvements in well-being may in turn have feedback effects on individuals' characteristics and activities in different domains of life. This point is potentially relevant for future research, but it has not been explicitly investigated yet in the extant literature that we have reviewed in the present paper.
} 
types of impacts. First, regarding changes in time use, it is now possible to carry out many of the same activities and tasks that human beings did in the past in a much more efficient and rapid manner than before. As illustrated at various points in section 5, time saving effects can lead to increase in hedonic well-being if individuals can avoid spending much of their working or spare time on activities that they do not enjoy. And they can also increase eudaimonic well-being if individuals are able to use this extra time in a meaningful way and for activities that may help to increase their capabilities, pursue personal growth and realize their inner potential. Second, Internet has fostered the emergence of a broad array of new gadgets, consumption items and online services, providing completely new opportunities that were not available in the past. The new online activities can potentially have direct positive effects on hedonic, evaluative and/or eudaimonic well-being. ${ }^{4}$ Third, the fact that Internet enables to gather, collect, organize and archive information in a much easier and more systematic way than before means that individuals can, both in their working life as well as in their spare time and social life, conduct daily tasks with greater efficiency, precision and quality. They can also access information and in turn learn and develop skills more quickly than before. This can certainly increase hedonic and evaluative well-being, but it can also have enhancing effects on personal characteristics such as capabilities and psychological functioning. Fourth, one of the most striking and commonly debated feature of Internet technologies relates to the increased possibilities they give to facilitate communication patterns and social interactions, for instance by means of distance and online communication. These new opportunities can in principle be used both in working life and in social life, potentially leading to great well-being benefits.

\section{Proposition 2: New risks and negative impacts.}

A balanced assessment does also require the consideration of the new risks and potential negative effects that Internet use may lead to. Sections 5 and 6 have presented various examples of these. In short, we argue that these possible negative effects can also be articulated along the four channels specified in our typology. First, time use changing patterns can sometimes have unfavorable and unintended consequences. For instance, in working life, while task automation

\footnotetext{
${ }^{4}$ A relevant question in this respect was recently pointed out by Komlos (2016). This work argues that innovations produced in the past may have had stronger employment and welfare effects compared to Internet-related innovations, since in the past technological innovations were often less close substitutes of older products, compared to digital innovations today. This conceptual argument is reasonable and intriguing, but we have not found empirical works investigating this question. This is an important topic for future research in this field.
} 
leads to productivity gains and benefits for highly skilled workers, it can also make other working tasks rapidly obsolete, increasing job insecurity for workers with lower level of e-skills. A different and more general example refers to individuals' adaptation times. Since Internet increases the pace at which human beings can achieve things and compare to others' achievements, a general risk is that many individuals will increasingly become unsatisfied with what they have, and thus continuously and restlessly aim at new goals instead of being contempt with what they already have. Second, the rapid creation of new Internet-based consumption goods and services inherently create new winners and new losers. E-skilled individuals are more likely to benefit from these new opportunities, whereas less educated workers run the risk of weakening their relative income, and may in other situations suffer from marginalization and social exclusion. Third, ICTs' inherent ability to disseminate and organize a rich amount of information has in recent years led to concerns about privacy issues, which arise when private organizations or public authorities get access to large amount of confidential information on individuals and can possibly use these for unethical purposes without the consent of the users. But there is also another important risk that was noted in section 5. Internet users can now easily get access to data and information about other users (in their community and elsewhere in the world), and thus change the way in which they form their reference groups for social and economic comparisons. This may present a risk and negatively affect well-being for those that are more vulnerable to comparisons with their higher-status "online neighbors". Finally, shifting the focus to Internet as a powerful communication tool, recent research noted in section 5 points out that some social groups and vulnerable individuals may be more prone to use the new communication technologies in an excessive manner than others. When this is the case, online technologies may not act as a vehicle of increased well-being but rather lead to isolation and as a factor hampering face-to-face interactions and an ordinary and active participation in the social community.

\section{Proposition 3: Indirect effects: personal characteristics as moderating factors.}

The relevant question is then: since the four functions outlined in this paper point out both positive effects as well as new risks, what are the factors that determine, for a given individual, whether positive impacts will prevail over potential risks? The answer to this question does largely depend on individuals' personal characteristics - and specifically psychological 
functioning, capabilities and own culture and beliefs. These personal characteristics moderate all mechanisms noted above, and they will ultimately determine whether and the extent to which Internet leads to greater positive or negative benefits.

To illustrate this point, consider first the role of psychological functioning (see sec. 6.1). This can undoubtedly have a moderating role on all other effects discussed above. For instance, it is reasonable to argue that an individual that has positive psychological functioning and awareness of the importance of self-realization and personal growth will be less focused on material and pecuniary aspects of life, less affected by social and economic comparisons that may damage well-being, and arguably less affected by the risks of excessive use and mismanagement of Internet services.

As for the role of capabilities, the two dimensions considered in this paper are health and education (sec. 6.2). These are obviously necessary pre-conditions for the realization of all other positive effects discussed above. Internet-based applications that improve individuals' health may not only have a direct and immediate impact on hedonic well-being (as argued in sec. 6.2), but also make it possible for those individuals to conduct regularly their daily life and hence realize the opportunities that ICTs offer in several domains of life. Similarly, education also has a moderating role on all other effects noted above. For example, when working life changes due to the emergence of new Internet-related demands and requirements, individuals with higher education and e-skills are more likely to experience better working conditions and higher relative income, avoiding the risks related to inequalities and skill obsolescence noted above.

Finally, culture and beliefs - religious, political and national - represent important mechanisms through which human beings shape their cognitive processes, ethical values and perceptions of their own status and achievements (sec. 6.3). It is therefore reasonable to argue that culture and beliefs play an important moderating role on all other effects noted in this survey. To illustrate, a culture (religious, or national) that is less oriented towards consumption and individualistic behavior may limit some of the risks associated with a mismanagement of Internet services, and instead lead individuals to value what they have and what their self-realization and inner potential call for.

In short, the third and final pillar of this theoretical framework can be pointed out as follows. Although the use of Internet increases individuals' set of opportunities, the extent to which these opportunities lead to greater well-being does largely depend on the personal characteristics of 
each individual: capabilities, psychological functioning, culture and beliefs. These therefore stand out as central dimensions to understand the links between Internet use and well-being.

\section{Conclusions}

The paper has carried out a survey of the empirical literature on the links between Internet use and well-being. After a systematic survey of different strands of research focused on distinct domains of life, we have pointed out an interdisciplinary framework that provides a summary overview of the complex set of impacts investigated in the literature. The main novelty presented in this paper is the new typology that distinguishes between four distinct channels: changes in time use, new activities, access to information and communication tools. This typology is important because, given the broad range of applications that Internet-related technologies can have in human life and the diverse set of effects that these can have on well-being, the study of this relationship does indeed represent a topic of large thematic breadth and high analytical complexity. This new typology enables to reduce this variety and complexity to a manageable set of dimensions, thus making it possible to analyze different effects into a single framework.

The main contribution of the paper is that it provides a systematic review of different strands of empirical research investigating the effects of Internet use on well-being, and a framework that summarizes the variety of different effects studied in the literature. This framework represents an ambitious interdisciplinary endeavor: it combines insights from different strands of research and different disciplines interested in human well-being such as economics, organizational studies, psychology and information systems research. It represents an attempt to bring together heterogeneous extant research on this theme, and so provide a more general structure to foster future research.

It is important to conclude by acknowledging three possible limitations of our analysis and related topics for future research. The first refers to the concept of scale. Different countries, regions and social groups have different rates of Internet penetration. How does Internet penetration rate affect the four mechanisms outlined in our typology? Scale can arguably have two different types of effects in our framework. On the one hand, the ICT diffusion literature points out that the probability that an individual adopts and actively uses ICT innovations partly depends on the number of users of the same technology in her country (region, social group). It 
is well-known that these peer effects are due to social learning, social pressure and network externalities. Hence, we may expect that the four impacts noted in the typology will be stronger the higher is the Internet penetration rate. On the other hand, as noted in section 5, the well-being literature points out that individuals tend to gradually adapt to their life conditions and to changes in this. Such adaptation effects may suggest that the four effects of Internet noted in our typology may possibly become weaker over time as the intensity of Internet use will increase. The combined impact of these two impacts - peer effects in Internet use and adaptation effects has not been studied yet in the literature, and it is an interesting topic for future research.

Second, our typology has pointed out four mechanisms that are conceptually distinct, since these are the different channels that have been empirically investigated in extant literature according to our literature review. We believe that it is important to disentangle these four effects in order to achieve a good understanding of the complex relationships between Internet use and well-being. However, by following this strategy, our paper has overlooked the potentially relevant fact that many Internet applications enable to carry out and manage various activities and actions at the same time. For instance, a SNS service can be used for communication activities in social life, interactions at work, social comparisons and access to information, among others. The possibility to connect and combine different human actions may well represent a key factor explaining why the Internet has become so widespread and it is having such profound effects on individuals' well-being.

Third, since our paper is based on a systematic survey of extant empirical research, the analysis has focused on Internet technologies, applications and services that are used at present, and on which there already exists empirical research to be surveyed. However, one may argue that new technological trajectories that are being developed at the moment - such as in particular artificial intelligence and robotics - may in the future be applied in combination with Internet, leading to profound changes in the interactions between human beings and machines. These future changes in the user interface will potentially have important effects in terms of individual users' wellbeing, which would arguably necessitate an extension of the typology presented in this paper. The present work has focused on extant empirical research, and it has therefore not been able to analyze these possible future developments. This is a fascinating topic for future research in this field. ${ }^{5}$

\footnotetext{
${ }^{5}$ We thank an anonymous referee of this journal for pointing out the three limitations reflections noted here.
} 


\section{Acknowledgments}

Financial support from the Research Council of Norway (Samansvar program) is gratefully acknowledged. We wish to thank the Editor and three reviewers of this journal, as well as Per Botolf Maurseth, Monica

Guillen-Royo, Fabio Sabatini, Adrian Smith and Ed Steinmueller, for their helpful comments and suggestions on a previous draft of the paper.

\section{References}

Andreassen, H. K., Bujnowska-Fedak, M. M., Chronaki, C. E., Dumitru, R. C., Pudule, I., et al. (2007). European citizens' use of E-health services: a study of seven countries. BMC public health, 7(1), 1.

Antonelli, C. (1998). Localized technological change, new information technology and the knowledgebased economy: the European evidence. Journal of Evolutionary Economics, 8(2), 177-198.

Armfield, G. G., and Holbert, R. L. (2003). The relationship between religiosity and Internet use. Journal of Media and Religion, 2(3), 129-144.

Arnfalk, P. (1999). Information technology in pollution prevention: Teleconferencing and telework used as tools in the reduction of work related travel. IIIEE DISSERTATION (1999: 1).

Asakawa, K. and Csikszentmihalyi, M. (1998). The quality of experience of Asian American adolescents in academic activities: An exploration of educational achievement. Journal of Research on Adolescence, $8(2), 241-262$.

Bala, H. and Venkatesh, V. (2015). Adaptation to information technology: A holistic nomological network from implementation to job outcomes. Management Science, 62(1), 156-179.

Bargh, J. and Katelyn YA. (2004). The Internet and social life. Annual Review of Psychology, 55, 573590.

Bhuller, M., Havnes, T., Leuven, E. and Mogstad, M. (2013). Broadband Internet: An Information Superhighway to Sex Crime? Review of Economic Studies, 80, 1237-1266.

Binder, M. (2013). Innovativeness and Subjective Well-Being. Social Indicators Research, 111, 561-578.

Blomquist, G. C., Berger, M. C. and Hoehn, J. P. (1988). New Estimates of Quality of Life in Urban Areas. The American Economic Review, 78(1), 89-107.

Bobillier Chaumon, M.-E., Michel, C., Tarpin Bernard, F. and Croisile, B. (2014). Can ICT improve the quality of life of elderly adults living in residential home care units? From actual impacts to hidden artefacts. Behaviour and Information Technology, 33(6), 574-590.

Bogomolov, A., Lepri, B., Staiano, J., Oliver, N. and Pianesi, F. (2014). Once Upon a Crime: Towards Crime Prediction from Demographics and Mobile Data. Paper presented at the Proceedings of the 16th International Conference on Multimodal Interaction, Istanbul, Turkey.

Borghesi, S. and Vercelli, A. (2012). Happiness and health: two paradoxes. Journal of Economic Surveys, 26(2), 203-233.

Boswell, W. R. and Olson-Buchanan, J. B. (2007). The Use of Communication Technologies After Hours: The Role of Work Attitudes and Work-Life Conflict. Journal of Management, 33(4), 592-610. 
Brooks, S. (2015). Does personal social media usage affect efficiency and well-being? Computers in Human Behavior, 46, 26-37.

Brown, K. W. and Ryan, R. M. (2003). The benefits of being present: Mindfulness and its role in psychological well-being. American Psychological Association, 84, 822-848.

Bruni, L. and Stanca, L. (2006). Income aspirations, television and happiness: Evidence from the world values survey. Kyklos, 59(2), 209-225.

Bruni, L. and Stanca, L. (2008). Watching alone: relational goods, television and happiness. Journal of Economic Behavior and Organization, 65(3), 506-528.

Burke, M., Marlow, C. and Lento, T. (2010). Social network activity and social well-being. Paper presented at the Proceedings of the SIGCHI conference on human factors in computing systems.

Caplan, S. E. (2003). Preference for online social interaction a theory of problematic Internet use and psychosocial well-being. Communication Research, 30(6), 625-648.

Carter, L. and Bélanger, F. (2005). The utilization of e-government services: citizen trust, innovation and acceptance factors. Information Systems Journal, 15(1), 5-25.

Castellacci, F. (2006). Innovation, diffusion and catching up in the fifth long wave. Futures, 38(7), 841863.

Castellacci, F. (2008). Technological paradigms, regimes and trajectories: Manufacturing and service industries in a new taxonomy of sectoral patterns of innovation. Research Policy, 37(6), 978-994.

Castellacci, F. and Viñas-Bardolet, C. (2017). Internet use and job satisfaction. TIK Working Paper No. 20170126, Centre for Technology, Innovation and Culture, University of Oslo.

Castellacci, F., Grodal, S., Mendonca, S. and Wibe, M. (2005). Advances and challenges in innovation studies. Journal of Economic Issues, 39(1), 91-121.

Castronova, E. and Wagner, G.G. (2011). Virtual life satisfaction. Kyklos, 64(3), 313-328.

Chen, Y. and Persson, A. (2002). Internet use among young and older adults: Relation to psychological well-being. Educational Gerontology, 28(9), 731-744.

Chesley, N. (2005). Blurring Boundaries? Linking Technology Use, Spillover, Individual Distress, and Family Satisfaction. Journal of Marriage and Family, 67(5), 1237-1248.

Christensen, H. S. (2011). Political activities on the Internet: Slacktivism or political participation by other means? First Monday, 16(2).

Clark, A. E. and Senik, C. (2010). Who Compares to Whom? The Anatomy of Income Comparisons in Europe. The Economic Journal, 120(544), 573-594.

Clark, A. E., Frijters, P. and Shields, M. A. (2008). Relative income, happiness, and utility: An explanation for the Easterlin paradox and other puzzles. Journal of Economic Literature, 95-144.

Cotten, S. R. (2008). Students' technology use and the impacts on well-being. New Directions for Student Services, 2008(124), 55-70.

Craglia, M., Leontidou, L., Nuvolati, G. and Schweikart, J. (2004). Towards the Development of Quality of Life Indicators in the 'Digital' City. Environment and Planning B: Planning and Design, 31(1), 51-64.

Crump, J. (2011). What are the police doing on Twitter? Social media, the police and the public. Policy and Internet, 3(4), 1-27.

Dalum, B., Freeman, C., Simonetti, R., von Tunzelmann, N. and Verspagen, B. (1999). Europe and the information and communication technologies revolution. The Economic Challenge for Europe: Adapting 
to Innovation Based Growth, Edward Elgar Publishing, Oslo/Rome/Maastricht.

Deaton, A. (2008). Income, health and wellbeing around the world: Evidence from the Gallup World Poll. Journal of Economic Perspectives, 22(2), 53.

Deci, E. L. and Ryan, R. M. (2000). The" what" and" why" of goal pursuits: Human needs and the selfdetermination of behavior. Psychological Inquiry, 11(4), 227-268.

Dickinson, A. and Gregor, P. (2006). Computer use has no demonstrated impact on the well-being of older adults. International Journal of Human-Computer Studies, 64(8), 744-753.

Diener, E. (2012). New findings and future directions for subjective well-being research. American psychologist, 67(8), 590-597.

Diener, E., Oishi, S. and Lucas, R. E. (2003). Personality, culture, and subjective well-being: Emotional and cognitive evaluations of life. Annual Review of Psychology, 54(1), 403-425.

Dolan, P. and Metcalfe, R. (2012). The relationship between innovation and subjective wellbeing.

Research Policy, 41(8), 1489-1498.

Dolan, P., Peasgood, T. and White, M. (2008). Do we really know what makes us happy? A review of the economic literature on the factors associated with subjective well-being. Journal of Economic Psychology, 29(1), 94-122.

Easterlin, R. A. (1974). Does economic growth improve the human lot? Some empirical evidence. Nations and Households in Economic Growth, 89-125.

Easterlin, R. A. (1995). Will raising the incomes of all increase the happiness of all? Journal of Economic Behavior and Organization, 27(1), 35-47.

Easton, M. (2016). Can big data help us predict where crime will strike? Retrieved from http://www.bbc.co.uk/guides/zqsg9qt

Edginton, C. R., Jordan, D. J., DeGraaf, D. G. and Edginton, S. R. (1995). Leisure and Life Satisfaction: Foundational Perspectives (4 ed., 3-29): Brown and Benchmark.

Ellison, C. G. (1991). Religious involvement and subjective well-being. Journal of Health and Social Behavior, 80-99.

Ellison, N.B., Steinfield, C. and Lampe, C. (2007). The benefits of Facebook "friends:" Social capital and college students' use of online social network sites. Journal of Computer-Mediated

Communication, 12(4), 1143-1168.

Engelbrecht, H. J. (2014). A general model of the innovation - subjective well-being nexus. Journal of Evolutionary Economics, 24(2), 377-397.

Erdogan, B., Bauer, T. N., Truxillo, D. M. and Mansfield, L. R. (2012). Whistle while you work a review of the life satisfaction literature. Journal of Management, 38(4), 1038-1083.

Fagerberg, J., Mowery, D. and Nelson, R. (2005). The Oxford Handbook of Innovation. Oxford University Press.

Fischer, R. and Boer, D. (2011). What is more important for national well-being: money or autonomy? A meta-analysis of well-being, burnout, and anxiety across 63 societies. Journal of Personality and Social Psychology, 101(1), 164.

Fisher, C. D. (2010). Happiness at work. International Journal of Management Reviews, 12(4), 384-412. Ford, G.S. and Ford, S.G. (2009). Internet use and depression among the elderly. Phoenix Center Policy 
Paper, 38.

Franzen, A. (2003). Social capital and the Internet: Evidence from Swiss panel data. Kyklos, 56(3), 341360.

Freeman, C. and Louçã, F. (2001). As time goes by: from the industrial revolutions to the information revolution: Oxford University Press.

Frey, B. S. and Stutzer, A. (1999). Measuring preferences by subjective well-being. Journal of Institutional and Theoretical Economics, 755-778.

Frey, B. S. and Stutzer, A. (2002). What can economists learn from happiness research? Journal of Economic Literature, 40(2), 402-435.

Frey, B. S., Benesch, C., and Stutzer, A. (2007). Does watching TV make us happy? Journal of Economic Psychology, 28(3), 283-313.

Frijters, P., and Van Praag, B. M. (1998). The effects of climate on welfare and well-being in Russia. Climatic Change, 39(1), 61-81.

Ganju, K.K., Pavlou, P.A. and Banker, R.D. (2015). Does information and communication technology lead to the well-being of nations? A Country-Level Empirical Investigation. MIS Quarterly, 40(2), 417430.

Gasper, D. (2005). Subjective and objective well-being in relation to economic inputs: puzzles and responses. Review of Social Economy, 63(2), 177-206.

GE Capital. (2013). GE Capital Retail Bank's Second Annual Shopper Study Outlines Digital Path to Major Purchases - 81\% Research Online Before Visiting Store. Retrieved from BussinessWire: http://www.businesswire.com/news/home/20130712005396/en/GE-Capital-Retail-Bank's-AnnualShopper-Study.

GhaffarianHoseini, A., Dahlan, N. D., Berardi, U., GhaffarianHoseini, A. and Makaremi, N. (2013). The essence of future smart houses: From embedding ICT to adapting to sustainability principles. Renewable and Sustainable Energy Reviews, 24, 593-607.

Golden, T.D. and Veiga, J.F. (2005). The impact of extent of telecommuting on job satisfaction: Resolving inconsistent findings. Journal of Management, 31(2), 301-318.

Graham, C. and Nikolova, M. (2013). Does access to information technology make people happier? Insights from well-being surveys from around the world. Journal of Socio-Economics, 44, 126-139.

Graham, C. and Nikolova, M. (2015). Bentham or Aristotle in the development process? An empirical investigation of capabilities and subjective well-being. World Development, 68, 163-179.

Greenstein, S. and McDevitt, R.C. (2011). The broadband bonus: Estimating broadband Internet's economic value. Telecommunications Policy, 35(7), 617-632.

Gross, E. F., Juvonen, J. and Gable, S. L. (2002). Internet use and well-being in adolescence. Journal of Social Issues, 58(1), 75-90.

Gui, B. and Stanca, L. (2010). Happiness and relational goods: well-being and interpersonal relations in the economic sphere. International Review of Economics, 57(2), 105-118.

Guillen Royo, M. (2007). Consumption and Wellbeing: Motives for Consumption and Needs Satisfiers in Peru, Doctoral dissertation, University of Bath.

Hamari, J., Sjöklint, M. and Ukkonen, A. (2015). The sharing economy: Why people participate in collaborative consumption. Journal of the Association for Information Science and Technology. 
Hamer, M., Stamatakis, E. and Mishra, G. D. (2010). Television- and Screen-Based Activity and Mental Well-Being in Adults. American Journal of Preventive Medicine, 38(4), 375-380.

Helliwell, J. F. (2006). Well-Being, Social Capital and Public Policy: What's New? The Economic Journal, 116(510), C34-C45.

Helliwell, J. F. and Huang, H. (2006). How's Your Government?: International Evidence Linking Good Government and Well-being. British Journal of Political Science, 38(4), 595-619.

Helliwell, J. F. and Huang, H. (2010). How's the job? Well-being and social capital in the workplace. Industrial and Labor Relations Review, 63(2), 205-227.

Helliwell, J. F. and Putnam, R. D. (2004). The social context of well-being. Philosophical Transactions Royal Society of London. Series B Biological Sciences, 1435-1446.

Helliwell, J.F. and Huang, H. (2013). Comparing the happiness effects of real and on-line friends. PloS One, 8(9), 72754.

Hendriks, P. (1999). Why share knowledge? The influence of ICT on the motivation for knowledge sharing. Knowledge and Process Management, 6(2), 91.

Hyll, W. and Schneider, L. (2013). The causal effect of watching TV on material aspirations: Evidence from the "valley of the innocent". Journal of Economic Behavior and Organization, 86, 37-51.

Innis, D. E. and La Londe, B. J. (1994). Customer service: the key to customer satisfaction, customer loyalty, and market share. Journal of Business Logistics, 15(1), 1.

Jackson, L. A., Fitzgerald, H. E., Zhao, Y., Kolenic, A., Von Eye, A., and Harold, R. (2008). Information Technology (IT) use and children's psychological well-being. CyberPsychology and Behavior, 11(6), 755-757.

Jacobsen, W. C., and Forste, R. (2011). The wired generation: Academic and social outcomes of electronic media use among university students. Cyberpsychology, Behavior, and Social Networking, 14(5), 275-280.

Kahneman, D., and Deaton, A. (2010). High income improves evaluation of life but not emotional wellbeing. Proceedings of the National Academy of Sciences, 107(38), 16489-16493.

Kahneman, D., and Krueger, A. B. (2006). Developments in the measurement of subjective well-being. The Journal of Economic Perspectives, 20(1), 3-24.

Kahneman, D., Diener, E., and Schwarz, N. (1999). Well-Being: The Foundations of Hedonic Psychology: Russell Sage Foundation.

Kasser, T. (2004). The Good Life or the Goods Life? Positive Psychology and Personal Well-Being in the Culture of Consumption. Positive Psychology in Practice, 55-67.

Kavetsos, G. and Koutroumpis, P. (2011). Technological affluence and subjective well-being. Journal of Economic Psychology, 32(5), 742-753.

Kluver, R., and Cheong, P. H. (2007). Technological Modernization, the Internet, and Religion in Singapore. Journal of Computer-Mediated Communication, 12(3), 1122-1142.

Ko, H.-C. K., Feng-Yang. (2009). Can blogging enhance subjective well-being through self-disclosure? CyberPsychology and Behavior, 12(1), 75-79.

Koku, E., Nazer, N., and Wellman, B. (2001). Netting scholars online and offline. American Behavioral Scientist, 44(10), 1752-1774.

Komlos, J. (2016). Has Creative Destruction Become More Destructive?. The BE Journal of Economic 
Analysis and Policy, 16(4).

Kramer, A. D., Guillory, J. E., and Hancock, J. T. (2014). Experimental evidence of massive-scale emotional contagion through social networks. Proceedings of the National Academy of Sciences, 111(24), 8788-8790.

Kraut, R. Kiesler, S., Boneva, B. Cummings, J., Helgeson, V. and Crawford, A. (2002). Internet Paradox Revisited. Journal of Social Issues, 58(1), 49-74.

Kraut, R., Patterson, M., Lundmark, V., Kiesler, S., Mukophadhyay, T. and Scherlis, W. (1998). Internet paradox: A social technology that reduces social involvement and psychological well-being?. American Pychologist, 53(9), 1017.

Lampe, C., Wohn, D. Y., Vitak, J., Ellison, N. B., and Wash, R. (2011). Student use of Facebook for organizing collaborative classroom activities. International Journal of Computer-Supported Collaborative Learning, 6(3), 329-347.

Layard, P. R. (2011). Happiness: Lessons from a New Science: Penguin UK.

Lee, P.S., Leung, L., Lo, V., Xiong, C. and Wu, T. (2011). Internet communication versus face-to-face interaction in quality of life. Social Indicators Research, 100(3), 375-389.

Lelkes, O. (2013). Happier and less isolated: Internet use in old age. Journal of Poverty and Social Justice, 21(1), 33-46.

Leung, L., and Lee, P. S. N. (2005). Multiple determinants of life quality: the roles of Internet activities, use of new media, social support, and leisure activities. Telematics and Informatics, 22(3), 161-180.

Li, C., Shi, X., and Dang, J. (2014). Online communication and subjective well-being in Chinese college students: The mediating role of shyness and social self-efficacy. Computers in Human Behavior, 34, 8995.

Li, J. L., Andrew; Barkley, Jacob E. (2015). Locus of control and cell phone use: Implications for sleep quality, academic performance, and subjective well-being. Computers in Human Behavior, 52, 450-457.

Li, S.M. and Chung, T.M. (2006). Internet function and Internet addictive behavior. Computers in Human Behavior, 22(6), 1067-1071.

Lohmann, S. (2015). Information technologies and subjective well-being: does the Internet raise material aspirations? Oxford Economic Papers, 67(3), 740-759.

MacKerron, G. (2012). Happiness economics from 35000 feet. Journal of Economic Surveys, 26(4), 705735.

Madge, C., Meek, J., Wellens, J., and Hooley, T. (2009). Facebook, social integration and informal learning at university: 'It is more for socialising and talking to friends about work than for actually doing work'. Learning, Media and Technology, 34(2), 141-155.

Manago, A. M., Taylor, T., and Greenfield, P. M. (2012). Me and my 400 friends: The anatomy of college students' Facebook networks, their communication patterns, and well-being. Developmental Psychology, 48(2), 369-380.

Martin, B. R. (2016). Twenty challenges for innovation studies. Science and Public Policy, 43(3), 432450.

Martin, L. and Omrani, N. (2015). An assessment of trends in technology use, innovative work practices and employees' attitudes in Europe. Applied Economics, 47(6), 623-638.

Mathers, M., Canterford, L., Olds, T., Hesketh, K., Ridley, K., et al. (2009). Electronic Media Use and Adolescent Health and Well-Being: Cross-Sectional Community Study. Academic Pediatrics, 9(5), 307- 
314.

McDool, E., Powell, P., Roberts, J. and Taylor, K. (2016). Social Media Use and Children's Wellbeing.

McKenna, K. Y. A., and Bargh, J. A. (2000). Plan 9 From Cyberspace: The Implications of the Internet for Personality and Social Psychology. Personality and Social Psychology Review, 4(1), 57-75.

Mesch, G. S. (2001). Social relationships and Internet use among adolescents in Israel. Social Science Quarterly, 82(2), 329-339.

Mitchell, M. E., Lebow, J. R., Uribe, R., Grathouse, H., and Shoger, W. (2011). Internet use, happiness, social support and introversion: A more fine grained analysis of person variables and internet activity. Computers in Human Behavior, 27(5), 1857-1861.

Moqbel, M., Nevo, S. and Kock, N. (2013). Organizational members' use of social networking sites and job performance: An exploratory study. Information Technology and People, 26(3), 240-264.

Moro, M., Brereton, F., Ferreira, S., and Clinch, J. P. (2008). Ranking quality of life using subjective well-being data. Ecological Economics, 65(3), 448-460.

Nie, N. H. (2001). Sociability, interpersonal relations, and the internet reconciling conflicting findings. American Behavioral Scientist, 45(3), 420-435.

O'Connor, P. (2008). User-generated content and travel: A case study on Tripadvisor.com. Information and Communication Technologies in Tourism, 47-58.

Oh, H. J., Ozkaya, E., and LaRose, R. (2014). How does online social networking enhance life satisfaction? The relationships among online supportive interaction, affect, perceived social support, sense of community, and life satisfaction. Computers in Human Behavior, 30, 69-78.

Oishi, S., Diener, E. F., Lucas, R. E., and Suh, E. M. (1999). Cross-cultural variations in predictors of life satisfaction: Perspectives from needs and values. Personality and Social Psychology Bulletin, 25(8), 980990.

Orpwood, R., Sixsmith, A., Torrington, J., Chadd, J., Gibson, G., et al. (2007). Designing technology to support quality of life of people with dementia. Technology and Disability, 19(2, 3), 103-112.

Park, N., Kee, K. F., and Valenzuela, S. (2009). Being immersed in social networking environment: Facebook groups, uses and gratifications, and social outcomes. CyberPsychology and Behavior, 12(6), 729-733.

Pea, R. e. a. (2012). Media use, face-to-face communication, media multitasking, and social well-being among 8-to 12-year-old girls. Developmental Psychology, 48(2), 327.

Pénard, T., Poussing, N., and Suire, R. (2013). Does the Internet make people happier?. The Journal of Socio-Economics, 46, 105-116.

Pincus, J. D. (1986). Communication satisfaction, job satisfaction, and job performance. Human Communication Research, 12(3), 395-419.

Prescott-Allen, R. (2001). Wellbeing of Nations; a country-by-country index of quality of life and the environment, International Development Research Centre.

Purcell, K., Heaps, A., Buchanan, J., and Friedrich, L. (2013). How teachers are using technology at home and in their classrooms. Pew Research Center's Internet and American Life Project.

Ramanna, K., and Tahilyani, R. (2012). I Paid a Bribe (Dot) Com. Harvard Business School Case, 112(078).

Roblyer, M. D., McDaniel, M., Webb, M., Herman, J., and Witty, J. V. (2010). Findings on Facebook in higher education: A comparison of college faculty and student uses and perceptions of social networking 
sites. The Internet and Higher Education, 13(3), 134-140.

Rotman, D., Vieweg, S., Yardi, S., Chi, E., Preece, J., et al. (2011). From slacktivism to activism: participatory culture in the age of social media. Paper presented at the CHI'11 Extended Abstracts on Human Factors in Computing Systems.

Rotondi, V., Stanca, L., and Tomasuolo, M. (2017). Connecting Alone: Smartphone Use, Quality of Social Interactions and Well-being, DEMS Working Paper 357.

Ryan, R. M., and Deci, E. L. (2001). On happiness and human potentials: A review of research on hedonic and eudaimonic well-being. Annual Review of Psychology, 52, 141-166.

Ryff, C. D. (1989). Happiness is everything, or is it? Explorations on the meaning of psychological wellbeing. Journal of Personality and Social Psychology, 57(6), 1069.

Ryff, C. D., and Keyes, C. L. M. (1995). The structure of psychological well-being revisited. Journal of Personality and Social Psychology, 69(4), 719-727.

Ryff, C. D., and Singer, B. (1998). The contours of positive human health. Psychological Inquiry, 9(1), 128.

Ryff, C. D., and Singer, B. (2008). Know thyself and become what you are: A eudaimonic approach to psychological well-being. Journal of Happiness Studies, 9(1), 13-39.

Sabatini, F. and Sarracino, F. (2017). Online networks and subjective well-being, Kyklos, 70(3): 456-480.

Sabatini, F. and Sarracino, F. (2016). Keeping up with the e-Joneses: Do online social networks raise social comparisons? MPRA Working Paper 69201.

Sacks, D. W. S., Betsey; Wolfers, Justin. (2012). The new stylized facts about income and subjective well-being. Emotion, 12(6), 1181.

Salanova, M., Cifre, E., and Martin, P. (2004). Information technology implementation styles and their relation with workers' subjective well-being. International Journal of Operations and Production Management, 24(1), 42-54.

Schmitt, M. (2013). Subjective Well-Being and Air Quality in Germany. SOEPpaper No. 541.

Sen, A. (1985). Well-being, agency and freedom: the Dewey lectures 1984. The Journal of Philosophy, 82(4), 169-221.

Sen, A. (1993). Capability and well-being. In M. Nussbaum and A. Sen (Eds.), The Quality of Life (pp. 30-54), World Institute for Development Economics Research.

Sengupta, A., and Chaudhuri, A. (2011). Are social networking sites a source of online harassment for teens? Evidence from survey data. Children and Youth Services Review, 33(2), 284-290.

Senik, C. (2005). Income distribution and well-being: what can we learn from subjective data? Journal of Economic Surveys, 19(1), 43-63.

Seo, Y. W., Chae, S. W., and Lee, K. C. (2015). The impact of absorptive capacity, exploration, and exploitation on individual creativity: Moderating effect of subjective well-being. Computers in Human Behavior, 42, 68-82.

Sirgy, M. J., Lee, D.-J., and Rahtz, D. (2007). Research on Consumer Well-Being (CWB): Overview of the Field and Introduction to the Special Issue. Journal of Macromarketing, 27(4), 341-349.

Smith, P. K., Mahdavi, J., Carvalho, M., Fisher, S., Russell, S., et al. (2008). Cyberbullying: Its nature and impact in secondary school pupils. Journal of Child Psychology and Psychiatry, 49(4), 376-385. 
Sorokowski, P., Sorokowska, A., Oleszkiewicz, A., Frackowiak, T., Huk, A., et al. (2015). Selfie posting behaviors are associated with narcissism among men. Personality and Individual Differences, 85, 123127.

Steinfield, C., Ellison, N. B., and Lampe, C. (2008). Social capital, self-esteem, and use of online social network sites: A longitudinal analysis. Journal of Applied Developmental Psychology, 29(6), 434-445.

Suh, E., Diener, E., Oishi, S., and Triandis, H. C. (1998). The shifting basis of life satisfaction judgments across cultures: Emotions versus norms. Journal of Personality and Social Psychology, 74(2), 482-493.

Suomi, R. (2000). Leapfrogging for modern ICT usage in the health care sector. ECIS 2000 Proc. 128.

Valenzuela, S. (2013). Unpacking the Use of Social Media for Protest Behavior: The Roles of Information, Opinion Expression, and Activism. American Behavioral Scientist, 57(7), 920-942.

Valkenburg, P. M., and Peter, J. (2009). Social consequences of the internet for adolescents a decade of research. Current Directions in Psychological Science, 18(1), 1-5.

Valkenburg, P. M., Peter, J., and Schouten, A. P. (2006). Friend networking sites and their relationship to adolescents' well-being and social self-esteem. CyberPsychology and Behavior, 9(5), 584-590.

Van der Doef, M., and Maes, S. (1999). The Job Demand-Control (-Support) Model and psychological well-being: A review of 20 years of empirical research. Work and Stress, 13(2), 87-114.

Veenhoven, R. (1984). Conditions of Happiness. D. Reidel Publishing Company.

Venkatesh, V., and Speier, C. (1999). Computer Technology Training in the Workplace: A Longitudinal Investigation of the Effect of Mood. Organizational Behavior and Human Decision Processes, 79, 1-28.

Warr, P. (1999). Well-being and the workplace, well-being: The foundations of hedonic psychology. In

Kahneman, D., Diener, Ed., and Schwarz, Well-Being: The Foundations of Hedonic Psychology, Russell Sage Foundation, 392-412.

Waterman, A. S. (1984). The Psychology of Individualism: Praeger Publishers.

Waterman, A. S. (1993). Two conceptions of happiness: Contrasts of personal expressiveness (eudaimonia) and hedonic enjoyment. Journal of Personality and Social Psychology, 64(4), 678-691.

Wei, R., and Leung, L. (1998). Owning and using new media technology as predictors of quality of life. Telematics and Informatics, 15(4), 237-251.

White, H., McConnell, E., Clipp, E., Bynum, L., Teague, C., et al. (1999). Surfing the net in later life: A review of the literature and pilot study of computer use and quality of life. Journal of Applied Gerontology, 18(3), 358-378.

Wilson, R. E., Gosling, S. D., and Graham, L. T. (2012). A review of Facebook research in the social sciences. Perspectives on Psychological Science, 7(3), 203-220.

Winter, S., Neubaum, G., Eimler, S. C., Gordon, V., Theil, J. (2014). Another brick in the Facebook wall: How personality traits relate to the content of status updates. Computers in Human Behavior, 34, 194202.

Wu, X., Zhu, X., Wu, G.-Q., and Ding, W. (2014). Data mining with big data. IEEE Transactions on Knowledge and Data Engineering, 26(1), 97-107.

Zhang, X., Zhang, X., and Chen, X. (2015). Happiness in the air: How does dirty sky affect subjective well-being? IFPRI Discussion Paper 1463.

Zhao, S. (2006). Do Internet users have more social ties? A call for differentiated analyses of Internet use. Journal of Computer-Mediated Communication, 11(3), 844-862. 
Table 1: Empirical studies on Internet use and well-being

\begin{tabular}{|c|c|c|c|c|c|c|}
\hline Article & Published in & $\begin{array}{l}\text { Dependent } \\
\text { variable }\end{array}$ & Key explanatory variable & Data & Empirical methods & $\begin{array}{l}\text { Country } \\
\text { focus }\end{array}$ \\
\hline \multicolumn{7}{|c|}{ In economics and management } \\
\hline $\begin{array}{c}\text { Venkatesh \& Speier } \\
\text { (1999) }\end{array}$ & $\begin{array}{l}\text { Organizational Behavior \& } \\
\text { Human Decision Processes }\end{array}$ & Job satisfaction & ICT training at work & Experimental & $\begin{array}{l}\text { Treatment-control } \\
\text { group comparison }\end{array}$ & US \\
\hline $\begin{array}{c}\text { Franzen } \\
(2003)\end{array}$ & Kyklos & Social capital & Internet use & Random Panel Survey & OLS & Switzerland \\
\hline $\begin{array}{l}\text { Salanova et al. } \\
\text { (2004) }\end{array}$ & $\begin{array}{l}\text { International Journal of } \\
\text { Operat. \& Prod. Manag. }\end{array}$ & Job satisfaction & ICT use at work & Survey of employees & MANOVA & Spain \\
\hline $\begin{array}{l}\text { Golden \& Veiga } \\
\text { (2005) }\end{array}$ & Journal of Management & Job satisfaction & Telecommuting & Survey of employees & Hierarchical model & US \\
\hline $\begin{array}{l}\text { Bruni \& Stanca } \\
\text { (2006) }\end{array}$ & Kyklos & Life satisfaction & TV watching & World Value Survey & OLS & $\begin{array}{l}\text { Cross- } \\
\text { country }\end{array}$ \\
\hline $\begin{array}{c}\text { Bruni \& Stanca } \\
\text { (2008) }\end{array}$ & $\begin{array}{c}\text { Journal of Economic } \\
\text { Behavior \& Organization }\end{array}$ & Life satisfaction & TV watching & World Value Survey & 2SLS & $\begin{array}{l}\text { Cross- } \\
\text { country }\end{array}$ \\
\hline $\begin{array}{c}\text { Castronova \& Wagner } \\
\text { (2011) }\end{array}$ & Kyklos & Life satisfaction & Use of Second Life & $\begin{array}{l}\text { Second Life Survey; } \\
\text { World Value Survey }\end{array}$ & OLS & $\begin{array}{l}\text { Cross- } \\
\text { country }\end{array}$ \\
\hline $\begin{array}{c}\text { Kavetsos \& Koutrompis } \\
\text { (2011) }\end{array}$ & $\begin{array}{c}\text { Journal of Economic } \\
\text { Psychology }\end{array}$ & Life satisfaction & Mobile phones and PCs & Eurobarometer & OLS & $\begin{array}{l}\text { Cross- } \\
\text { country }\end{array}$ \\
\hline $\begin{array}{l}\text { Lelkes } \\
(2012)\end{array}$ & Working paper & Life satisfaction & Internet use & $\begin{array}{c}\text { European Social } \\
\text { Survey }\end{array}$ & Logit & $\begin{array}{l}\text { Cross- } \\
\text { country }\end{array}$ \\
\hline $\begin{array}{c}\text { Bhuller et al. } \\
\text { (2013) }\end{array}$ & Review Economic Studies & Sex crime & Broadband Internet & Register and surveys & IV & Norway \\
\hline $\begin{array}{c}\text { Graham \& Nikolova } \\
\text { (2013) }\end{array}$ & Journal of Socio-Economics & Life satisfaction & Internet access & Gallup World Poll & Ordered logit & $\begin{array}{l}\text { Cross- } \\
\text { country }\end{array}$ \\
\hline $\begin{array}{c}\text { Katz \& Koutrompis } \\
\text { (2013) }\end{array}$ & Technovation & Life satisfaction & Digitalization index & $\begin{array}{c}\text { World Database } \\
\text { of Happiness }\end{array}$ & OLS & $\begin{array}{l}\text { Cross- } \\
\text { country }\end{array}$ \\
\hline $\begin{array}{l}\text { Penard et al. } \\
\text { (2013) }\end{array}$ & Journal of Socio-Economics & Life satisfaction & Internet use intensity & European Value Survey & 2SLS & Luxemburg \\
\hline $\begin{array}{l}\text { Moqbel et al. } \\
\text { (2013) }\end{array}$ & $\begin{array}{c}\text { Information Technology } \\
\text { \& People }\end{array}$ & Job satisfaction & SNS use & Survey of employees & $\begin{array}{l}\text { Structural equation } \\
\text { modelling }\end{array}$ & US \\
\hline $\begin{array}{c}\text { Hyll \& Schneider } \\
\text { (2013) }\end{array}$ & $\begin{array}{c}\text { Journal of Economic } \\
\text { Behavior \& Organization }\end{array}$ & Material aspirations & TV watching & CIYR Survey & $\begin{array}{c}\text { Bivariate ordered } \\
\text { probit }\end{array}$ & $\begin{array}{c}\text { East } \\
\text { Germany }\end{array}$ \\
\hline $\begin{array}{c}\text { Sabatini \& Sarracino } \\
\text { (2017) }\end{array}$ & Kyklos & Life satisfaction & Social media use & $\begin{array}{c}\text { Multipurpose Survey } \\
\text { on Households }\end{array}$ & $\begin{array}{l}\text { 2SLS; Structural } \\
\text { equation modelling }\end{array}$ & Italy \\
\hline
\end{tabular}




\begin{tabular}{|c|c|c|c|c|c|c|}
\hline $\begin{array}{l}\text { Lohmann } \\
(2015)\end{array}$ & Oxford Economic Papers & Life satisfaction & Internet access and use & $\begin{array}{c}\text { EU-SILC Survey; } \\
\text { World Value Survey }\end{array}$ & OLS; ordered probit & $\begin{array}{l}\text { Cross- } \\
\text { country }\end{array}$ \\
\hline $\begin{array}{c}\text { Martin \& Omrani } \\
\quad(2015)\end{array}$ & Applied Economics & Job satisfaction & Internet use & $\begin{array}{l}\text { European Working } \\
\text { Conditions Survey }\end{array}$ & OLS & $\begin{array}{l}\text { Cross- } \\
\text { country }\end{array}$ \\
\hline $\begin{array}{c}\text { Sabatini \& Sarracino } \\
\text { (2015) }\end{array}$ & Working paper & Income satisfaction & SNS use & $\begin{array}{l}\text { Multipurpose Survey } \\
\text { on Households }\end{array}$ & $2 \mathrm{SLS}$ & Italy \\
\hline $\begin{array}{c}\text { Bala \& Venkatesh } \\
\text { (2016) }\end{array}$ & Management Science & Job satisfaction & ICT use at work & Firm field studies & Partial least squares & US \\
\hline $\begin{array}{l}\text { Rotondi et al. } \\
\text { (2016) }\end{array}$ & Working paper & Life satisfaction & Smartphone use & $\begin{array}{l}\text { Multipurpose Survey } \\
\text { on Households }\end{array}$ & 2SLS & Italy \\
\hline $\begin{array}{l}\text { Ganju et al. } \\
\text { (2015) }\end{array}$ & MIS Quarterly & Life satisfaction & $\begin{array}{l}\text { Internet users; } \\
\text { mobile phones }\end{array}$ & Gallup World Poll & 2SLS; biclustering & $\begin{array}{l}\text { Cross- } \\
\text { country }\end{array}$ \\
\hline $\begin{array}{l}\text { McDool et al. } \\
\text { (2016) }\end{array}$ & Working paper & Life satisfaction & Internet use & $\begin{array}{c}\text { Household } \\
\text { Longitudinal Study }\end{array}$ & $\begin{array}{l}\text { IV random effects } \\
\text { ordered probit }\end{array}$ & UK \\
\hline $\begin{array}{l}\text { Castellacci \& Viñas- } \\
\text { Bardolet (2017) }\end{array}$ & Working paper & Job satisfaction & Internet use at work & $\begin{array}{l}\text { European Working } \\
\text { Conditions Survey }\end{array}$ & $\begin{array}{c}\text { Bivariate } \\
\text { ordered probit }\end{array}$ & $\begin{array}{l}\text { Cross- } \\
\text { country }\end{array}$ \\
\hline \multicolumn{7}{|c|}{ In computer science and psychology } \\
\hline $\begin{array}{l}\text { Kraut et al. } \\
\text { (1998) }\end{array}$ & American Psychologist & $\begin{array}{l}\text { Psychological } \\
\text { well-being }\end{array}$ & Internet use & Own repeated surveys & OLS & US \\
\hline $\begin{array}{l}\text { Wei \& Leung } \\
\text { (1998) }\end{array}$ & Telematics and Informatics & Quality of life & New media use & Own survey & $\begin{array}{c}\text { OLS; } \\
\text { Hierarchical model }\end{array}$ & Hong Kong \\
\hline $\begin{array}{c}\text { Chen and Persson } \\
\text { (2002) }\end{array}$ & Educational Gerontology & $\begin{array}{l}\text { Psychological } \\
\text { well-being }\end{array}$ & Internet use & Own survey & ANOVA & US \\
\hline $\begin{array}{l}\text { Gross et al. } \\
(2002)\end{array}$ & Journal of Social Issues & $\begin{array}{l}\text { Psychological } \\
\text { well-being }\end{array}$ & Internet use & Diary and survey data & Hierarchical model & US \\
\hline $\begin{array}{l}\text { Kraut et al. } \\
\quad(2002)\end{array}$ & Journal of Social Issues & $\begin{array}{l}\text { Psychological } \\
\text { well-being }\end{array}$ & Internet use & Own repeated surveys & Panel regressions & US \\
\hline $\begin{array}{l}\text { Caplan } \\
(2003)\end{array}$ & Communication Research & $\begin{array}{l}\text { Psychosocial } \\
\text { well-being }\end{array}$ & Online interactions & Own survey & Hierarchical model & US \\
\hline $\begin{array}{l}\text { Chesley } \\
(2005)\end{array}$ & $\begin{array}{c}\text { Journal of Marriage } \\
\text { and Family }\end{array}$ & $\begin{array}{l}\text { Psychological } \\
\text { distress }\end{array}$ & E-mail and Internet use & $\begin{array}{l}\text { Cornell Couples and } \\
\text { Careers Study }\end{array}$ & $\begin{array}{l}\text { Structural equation } \\
\text { modelling }\end{array}$ & US \\
\hline $\begin{array}{l}\text { Leung \& Lee } \\
\text { (2005) }\end{array}$ & Telematics and Informatics & Quality of life & Internet use & Own survey & Hierarchical model & Hong Kong \\
\hline $\begin{array}{l}\text { Valkenburg et al. } \\
\text { (2006) }\end{array}$ & $\begin{array}{c}\text { Cyberpsychology } \\
\text { \& Behavior }\end{array}$ & Life satisfaction & Online interactions & Own survey & $\begin{array}{l}\text { Structural equation } \\
\text { modelling }\end{array}$ & Netherlands \\
\hline $\begin{array}{l}\text { Zhao } \\
\text { (2006) }\end{array}$ & $\begin{array}{l}\text { Journal of Computer- } \\
\text { Mediated Communication }\end{array}$ & Social ties & Internet use & General Social Survey & OLS & US \\
\hline
\end{tabular}




\begin{tabular}{|c|c|c|c|c|c|c|}
\hline $\begin{array}{c}\text { Contarello \& Sarrica } \\
\text { (2007) }\end{array}$ & $\begin{array}{l}\text { Computers in Human } \\
\text { Behavior }\end{array}$ & Social well-being & Perceived Internet use & Own survey & $\begin{array}{l}\text { Correspondence } \\
\text { analysis }\end{array}$ & Italy \\
\hline $\begin{array}{l}\text { Ellison et al. } \\
\text { (2007) }\end{array}$ & $\begin{array}{l}\text { Journal of Computer- } \\
\text { Mediated Communication }\end{array}$ & $\begin{array}{l}\text { Life satisfaction; } \\
\text { Social capital }\end{array}$ & Facebook use & Own survey & OLS & US \\
\hline $\begin{array}{l}\text { Cotton } \\
(2008)\end{array}$ & $\begin{array}{c}\text { New Directions } \\
\text { for Student Services }\end{array}$ & $\begin{array}{l}\text { Psychological } \\
\text { well-being }\end{array}$ & Internet use & $\begin{array}{l}\text { College Internet } \\
\text { Use Study }\end{array}$ & Path analysis & US \\
\hline $\begin{array}{l}\text { Jackson et al. } \\
\quad(2008)\end{array}$ & $\begin{array}{c}\text { CyberPsychology } \\
\text { \& Behavior }\end{array}$ & $\begin{array}{l}\text { Psychological } \\
\text { well-being }\end{array}$ & Internet use & Own survey & Hierarchical model & US \\
\hline $\begin{array}{l}\text { Steinfield et al. } \\
\text { (2008) }\end{array}$ & $\begin{array}{c}\text { Journal of Applied } \\
\text { Developmental Psychology }\end{array}$ & $\begin{array}{l}\text { Life satisfaction; } \\
\text { psychol. well-being }\end{array}$ & Facebook use & Own survey & OLS & US \\
\hline $\begin{array}{l}\text { Ford \& Ford } \\
\text { (2009) }\end{array}$ & Working paper & $\begin{array}{l}\text { Psychological } \\
\text { well-being }\end{array}$ & Internet use & $\begin{array}{c}\text { Health and } \\
\text { Retirement Study }\end{array}$ & $\begin{array}{l}\text { Propensity score } \\
\text { matching }\end{array}$ & US \\
\hline $\begin{array}{l}\text { Ko \& Kuo } \\
\text { (2009) }\end{array}$ & $\begin{array}{c}\text { Cyberpsychology } \\
\text { \& Behavior }\end{array}$ & $\begin{array}{l}\text { Subjective } \\
\text { well-being }\end{array}$ & Blogging & Own survey & $\begin{array}{l}\text { Structural equation } \\
\text { modelling }\end{array}$ & Taiwan \\
\hline $\begin{array}{l}\text { Madge et al. } \\
\text { (2009) }\end{array}$ & $\begin{array}{l}\text { Learning, Media } \\
\text { and Technology }\end{array}$ & Social ties & Facebook use & Own survey & Qualitative analysis & UK \\
\hline $\begin{array}{l}\text { Park et al. } \\
\text { (2009) }\end{array}$ & $\begin{array}{c}\text { Cyberpsychology } \\
\text { \& Behavior }\end{array}$ & Life satisfaction & $\begin{array}{l}\text { Facebook groups } \\
\text { interactions }\end{array}$ & Own survey & Hierarchical model & US \\
\hline $\begin{array}{c}\text { Burke et al. } \\
\text { (2010) }\end{array}$ & Conference proceeding & $\begin{array}{l}\text { Life satisfaction; } \\
\text { Social capital }\end{array}$ & Facebook use & $\begin{array}{l}\text { Own survey; } \\
\text { Facebook data }\end{array}$ & OLS & US \\
\hline $\begin{array}{l}\text { Jacobsen \& Forste } \\
\text { (2011) }\end{array}$ & $\begin{array}{c}\text { Cyberpsychology, Behavior } \\
\text { \& Social Networking }\end{array}$ & Social capital & Electronic media use & Diary and survey data & OLS & US \\
\hline $\begin{array}{l}\text { Kivunike et al. } \\
\text { (2011) }\end{array}$ & $\begin{array}{l}\text { Information Technology } \\
\text { for Development }\end{array}$ & Quality of life & Perception of ICT benefits & Own survey & ANOVA & Uganda \\
\hline $\begin{array}{l}\text { Lee et al. } \\
\text { (2011) }\end{array}$ & Social Indicators Research & Life satisfaction & Online communication & Own survey & OLS & China \\
\hline $\begin{array}{l}\text { Mitchell et al. } \\
\text { (2011) }\end{array}$ & $\begin{array}{l}\text { Computers in Human } \\
\text { Behavior }\end{array}$ & Hedonic well-being & Online activities & Own survey & OLS and ANOVA & US \\
\hline $\begin{array}{l}\text { Manago et al. } \\
\text { (2012) }\end{array}$ & Developmental Psychology & Life satisfaction & Facebook use & Own survey & OLS & US \\
\hline $\begin{array}{l}\text { Helliwell \& Huang } \\
\text { (2013) }\end{array}$ & Plos One & $\begin{array}{l}\text { Life satisfaction; } \\
\text { happiness }\end{array}$ & Online network size & $\begin{array}{l}\text { Happiness Monitor } \\
\text { Survey }\end{array}$ & OLS & Canada \\
\hline $\begin{array}{l}\text { Li et al. } \\
\text { (2014) }\end{array}$ & $\begin{array}{l}\text { Computers in Human } \\
\text { Behavior }\end{array}$ & $\begin{array}{l}\text { Subjective } \\
\text { well-being }\end{array}$ & Online communication & Own survey & $\begin{array}{l}\text { Structural equation } \\
\text { modelling }\end{array}$ & China \\
\hline $\begin{array}{l}\text { Oh et al. } \\
(2014)\end{array}$ & $\begin{array}{c}\text { Computers in Human } \\
\text { Behavior }\end{array}$ & Life satisfaction & $\begin{array}{l}\text { Online network size } \\
\text { and frequency of use }\end{array}$ & Diary and survey data & Hierarchical model & US \\
\hline $\begin{array}{l}\text { Li et al. } \\
\text { (2015) }\end{array}$ & $\begin{array}{c}\text { Computers in Human } \\
\text { Behavior }\end{array}$ & $\begin{array}{l}\text { Life satisfaction; } \\
\text { sleep quality }\end{array}$ & Cell phone use & Own survey & $\begin{array}{l}\text { Structural equation } \\
\text { modelling }\end{array}$ & US \\
\hline $\begin{array}{l}\text { Brooks } \\
(2015)\end{array}$ & $\begin{array}{c}\text { Computers in Human } \\
\text { Behavior }\end{array}$ & Happiness & Social media use & Experimental & $\begin{array}{c}\text { Composite reliability } \\
\text { analysis }\end{array}$ & US \\
\hline
\end{tabular}


Function

time use
New
activities
Access to
information
Communication
tools

\section{Change in} time use

New activities

Access to information

\section{Communication tools}

\section{Channel}

\section{SOCIAL LIFE}

Internet use can increase social pressure and stress.

It may enable a more efficient management of social activities

New modes of socializing and meeting people

It creates worldwide social reference groups. It may strengthen trust and social capital

Greater opportunities for distance communication, but also more opportunities for misuse

\section{CONSUMPTION}

Purchase of goods and services online has time saving effects. But also increased risk of scams and theft

$$
\begin{aligned}
& \text { New ICT-based } \\
& \text { consumer services }
\end{aligned}
$$

More systematic information on consumption items. Greater risks for consumers' privacy

Improved communication with service providers, but more computer-generated responses

\section{WORK QUALITY}

\section{Change in time use}

New activities

Access to information

Communication tools
Task automation increases efficiency and frees up time, but it can make some occupations obsolete

New occupations can provide security and personal control, positive for well-being - yet these demand higher education and can replace other occupations Easier information access improves quality of work

Increased opportunities for communication can foster social capital and knowledge sharing, but also distract the workers and make them less efficient
SNS; Facebook events

Mobile apps

(Tinder, Pokémon GO)

Social Network Feed, International News

Mobile phones; Skype; SNS
E-commerce;

Online banking

Collab. consumption services (Uber, Airbnb Kickstarter)

Rating systems (TripAdvisor); Business on Facebook

Online customer service

\section{IT platforms; Database systems}

IT jobs in development, design and coding

Intranet, Online scientific journals; Online Encyclopedias

Email;

Facebook at Work 
Table 2 (cont.)

Function

Channel

Examples

\section{RELATIVE INCOME}

Change in time use

New activities

Access to information

Communication tools

\section{Change in time use \\ New activities \\ Access to information \\ Communication tools}

Change in
time use
New
activities
Access to
information
Communication
tools

Task automation affects relative income of high- and low-skilled

Creation of new

services, while making other activities obsolete

Changing reference group boundaries.

Broader understanding of own absolute income

More efficient business-to-business communication, creating personalized offers for customers

\section{PHYSICAL ENVIRONMENT}

Increased efficiency of transportation infrastructures

New green technologies and energy informatics can provide better climate for citizens.

But they may also open for new misuses of personal data.

Data gathering and monitoring of climate and environment

Online communication fosters awareness of environmental friendly activities. Can also create 'Slacktivism'

\section{INSTITUTIONAL ENVIRONMENT}

\author{
Automation and online public services \\ lead to time saving effects
}

New ICT-based applications increase monitoring and public safety, but can also be used for mass surveillance

Automation and online public services increases quality and clarity of public regulations

SNS communication fosters civic engagement and participation in public processes
Changing role of bank tellers

Collaborative consumption services (Uber and Airbnb)

Online public tax records

Global production networks; Online personalized marketing

Digital systems for public transportation

Thermostat that saves energy by learning user's habits

Online Real Time Air Quality of the World

Online Environmental Communities

E-government services such as taxes and license renewal

Big data analysis for crime prevention

Online Governmental Platforms; bribes reporting

SNS activism events 


\section{Table 3: Effects of Internet through personal characteristics}

\section{Function}

\author{
Channel \\ PSYCHOLOGICAL FUNCTIONING

$$
\text { New services focused on lifestyle changes }
$$$$
\text { and personal growth }
$$

Automation of tedious activities frees up time that can be used for other more psychologically rewarding activities

\section{Access to information}

\section{Communication tools}

\section{Change in time use}

New activities

\section{Access to} information

\section{Communication tools}

Greater opportunities for self-realization. Increased exposure to people outside ones' comparison groups can spur non-psychologically rewarding lifestyle models New modes of communication change the way we interact with others and affect our psychological functioning

\section{CAPABILITIES (HEALTH AND EDUCATION)}

\author{
Increased efficiency of public health \\ and educational services
}

Individuals can monitor their own health and educational progress, and be nudged to improve capabilities by ICT apps. But personal data may also be exploited for commercial purposes

Information access improves quality of health and education. But excessive available information may be overwhelming

Mobile and distance communication provides new opportunities for health and educational activities

\section{CULTURE AND BELIEFS}

\section{Change in time use \\ New activities \\ Access to information \\ Communication tools}

Organization of cultural, political and religious events becomes more rapid and efficient

SNS services can induce narcissism, self-disclosure and living a more self-centered lifestyle

Internet-based information makes national cultures more homogenous

Mobile communication makes national cultures more homogenous
Examples

Online organization of travel activities

Fitness

and meditational apps

Online encyclopedias; Instagram, Snapchat, YouTube

SNS

Digital health records; Itslearning education platform

Wearable health monitors; applications for learning and academic focus

Online patient journals;

Google, WebMD, Kahn Academy, Coursera Elderly patients communication; teacher-students interactions

\section{SNS}

News feeds, status updates, "selfies"

Google; Wikipedia

Mobile phones; SNS; Video conferences 
Figure 1: A theoretical framework on the effects of Internet use on well-being

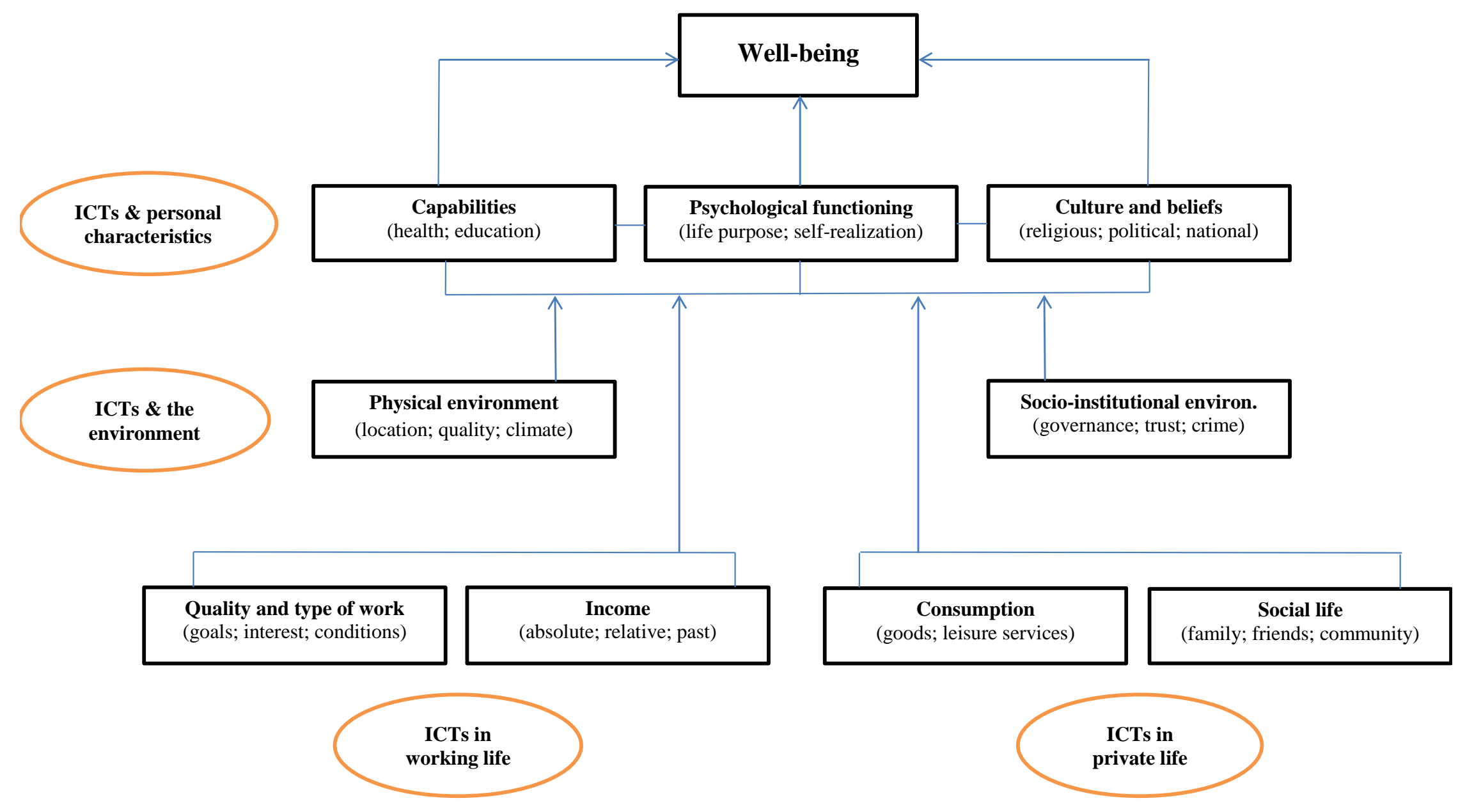

